\title{
Escrita missionária e a questão da autonomia da escrita alfabética
}

\author{
Maria Cândida Drumond Mendes Barros \\ Museu Emilio Goeldi (Pará/Brasil)
}

\section{Abstract}

The aim of this paper is to juxtapose the theme of missionary literacy with a theoretical discussion of the attribute of autonomy with reference to literacy. By missionary literacy we mean the alphabetic typographic writing system created by missionaries as part of the evangelical process of biblical translation. In particular, this study focuses on those cases of missionary literacy based on linguistics, for which the Summer Institute of Linguistics (SIL) is of special significance.

In so far as the debate on autonomy is concerned, we refer to the controversy between the autonomy model of Goody, Ong and Olson and the ideological model of Street. The relevance of the question of autonomy in relation to the theme of missionary literacy has its origins in the Protestant tradition, that the text is its own interpreter (Olson 1991), an autonomous conception of the written text. This concept of literacy is a special expression of religious literal meaning, and therefore allows us to focus attention on the particular feature of literacy in the missionary domain. 


\section{1 - INTRODUÇÃO}

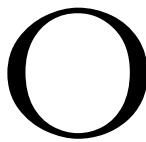

objetivo do trabalho é contrapor o tema das escritas missionárias à discussão teórica sobre o atributo de autonomia referido à escrita. Por escrita missionária, entendem-se as escritas alfabéticas-tipográficas em línguas ágrafas criadas por missionários evangélicos como parte do processo de tradução bíblica. Em particular, interessarão os casos de escritas missionárias fundamentadas na lingüística, dos quais o Summer Institute of Linguistics (SIL) é um caso paradigmático.

A proposta é traçar uma análise histórica e sociolingüística dessa tradição de escrita. A análise histórica procurará caracterizar o modelo de escrita da tradição evangélica, implantado pelas missões desde o século XIX entre populações ágrafas. A análise sociolingüística enfocará uma situação particular de leitura no contexto missionário, que refletiria as características dessa tradição de escrita.

Quanto ao debate teórico sobre autonomia, está-se referindo à controvérsia entre o modelo autônomo (Goody, 1968, Ong, 1982 e Olson, 1991a) e ideológico (Street, 1995). O primeiro grupo representa aqueles autores que atribuíram relevância ao valor de autonomia na definição de escrita. O segundo grupo critica o conceito de autonomia como qualidade intrínseca da escrita, considera-o um mito e utiliza o termo como rótulo para identificar o primeiro grupo de autores.

A proposta teórica do trabalho será articular as posições dessas duas correntes, conservando, por exemplo, o conceito de texto autônomo, porém definindo-o como um padrão cultural específico de escrita missionária e não como qualidade do sistema alfabético.

A relevância da questão da autonomia em relação ao tema da escrita missionária é por ser esta originária da tradição protestante, 
que postula que o texto é seu próprio intérprete (Olson, 1991a), uma concepção autônoma do texto escrito. Essa concepção de escrita será considerada como uma expressão da noção religiosa do sentido literal, permitindo, dessa maneira, abordar um traço particular da escrita no contexto evangélico.

O roteiro a ser seguido no trabalho será:

a) revisar a noção de autonomia na literatura sobre escrita, limitando-se às questões relativas a sua oposição à oralidade e sua relação com o conceito de não-ambigüidade;

b) propor uma concepção de "texto autônomo" que combine elementos do modelo autônomo e do ideológico na análise da escrita no contexto evangélico;

c) traçar uma caracterização histórica da escrita missionária de base lingüística, com atenção ao SIL no México e no Brasil;

d) apontar traços de uma concepção autônoma da escrita no interior do movimento de tradução bíblica através do uso da Lingüística como modelo ortográfico;

e) descrever uma situação de diálogo própria da tradução bíblica missionária, que tem o papel de um evento literário importante na socialização do valor da autonomia como concepção de escrita.

O trabalho sobre escrita missionária se restringirá às concepções vigentes nos documentos oficiais utilizados pelas missões na formação de seus membros, tais como artigos de periódicos especializados para o tradutor-missionário, documentos das sociedades bỉblicas ditando as regras a seguir nas traduções ou ainda alguns textos de divulgação do trabalho missionário nas comunidades evangélicas. Não caberá aqui a análise do uso que os grupos a serem convertidos fazem da escrita introduzida pelos missionários. Pode haver uma distância entre o modelo missionário de escrita e o que efetivamente as comunidades ágrafas concebem e usam. Na conclusão, far-se-á menção a alguns casos de movimentos messiânicos nos quais ocorreu essa distância. 


\section{2 - A CONTROVÉRSIA EM TORNO DA AUTONOMIA COMO VALOR DA ESCRITA}

O debate entre modelo autônomo e ideológico apresenta uma variedade de pontos de discórdias na forma de conceber a escrita. Eles se opõem na forma de conceber a relação entre escrita e oralidade (polaridade ou interconexão), no tocante à existência ou não de uma relação de causa e efeito entre o tipo de sistema de escrita e formas de pensamento, e ainda na forma de definir o papel da escrita numa comunidade (seu impacto sobre a comunidade ou o papel agente da comunidade na forma de uso da escrita).

A revisão do debate entre os dois modelos se restringirá às divergências em relação ao atributo de "autonomia" que têm relevância para compor a idéia de sentido literal no contexto da escrita missionária, tais como:

a) escrita independente da oralidade;

b) escrita não-ambígua.

Nessa revisão da literatura sobre autonomia usar-se-ão os artigos clássicos de Olson, Goody e Ong, referidos na crítica do modelo ideológico. Não estão incluídos os textos mais atuais dos autores do modelo autônomo (Olson, 1997, por exemplo), onde já não se encontra mais a mesma definição do valor de autonomia ou a suposição da polaridade entre escrita e oralidade.

\section{1 - A recorrência de autonomia}

Em Goody (1968), Olson (1991a) e Ong (1982), a noção de autonomia é válida apenas para a escrita e aparece associada a uma família de sentidos que inclui: permanente, fixo, não-ambíguo, descontextualizado, abstrato, próprio para o pensamento lógico, etc. Em oposição, estaria a oralidade, caracterizada pelos antônimos desses atributos. O valor da "autonomia" é definido como sinônimo de "escrita completa" ou "real" (full writing e real writing) (Goody/ Watt, 1968). 
As concepções sobre autonomia que interessarão para a análise da escrita missionária são:

a) sua definição como um modo de comunicação independente da oralidade;

b) sua vinculação a um tipo particular de sistema de escrita (alfabeto);

c) sua definição como "texto autônomo", ou seja, um estilo de linguagem próprio da escrita, que teria surgido com a ciência e o movimento protestante.

\section{A) Uso da escrita com independência da oralidade}

Goody (1968) propõe autonomia como um modo peculiar de comunicação pela escrita, usado independentemente de qualquer contraparte oral. Uma escrita autônoma permitiria que o texto fosse lido sem ambigüidades, independente de informações vindas do contexto ou pela oralidade para sua compreensão. Por exemplo, um texto escrito usado de forma associada a cânticos e a memorização não preencheria a condição de escrita autônoma e se configuraria como uma situação de escrita restrita.

Para Goody e Watt (1968), as sociedades com tradição de escrita autônoma e as sociedades orais se oporiam em relação à forma de transmissão cultural. Em oposição ao funcionamento autônomo, estariam as sociedades orais, nas quais a transmissão cultural ocorreria de uma forma homeostática. O termo homeostático é resgatado da forma de funcionamento de um organismo, quando há o equilíbrio e integração do funcionamento de diferentes partes. Dessa forma, numa sociedade oral, a transmissão cultural se faria através de operações inconscientes da memória e de ajustes que o contador faz em relação a sua audiência (Goody/Watt, 1968: 44). Esse mecanismo homeostático seria semelhante ao que é trabalhado nas análises de representações coletivas, nas quais, por exemplo, a estrutura de parentesco de uma sociedade estaria reproduzida e reforçada ao nível da organização espacial das casas na comunidade. 
A diferença entre o funcionamento homeostático e o autônomo de uma sociedade é exemplificada por Goody e Watt no caso dos Tiv, na Nigéria. As genealogias entre os Tiv eram usadas como formas mnemônicas das relações sociais sincrônicas e usadas nos casos de justiça interna. Os administradores coloniais ingleses transcreveram essas genealogias para o papel, e, 40 anos depois, quiseram usar o documento como forma de resolução de um problema interno. Para os ingleses, a genealogia documentada por escrito deveria ser sempre a mesma em qualquer contexto - por isso seu caráter autônomo. Porém, para os Tiv, o documento não tinha valor como verdadeiro. Nesse caso, a genealogia era usada homeostaticamente para refletir situações atuais do grupo, e não como um documento histórico autônomo como proposto pelos ingleses.

\section{B) Autonomia como qualidade exclusiva do sistema de escrita alfabético}

Apenas o sistema de escrita alfabético teria a qualidade de autonomia, entendida como a possibilidade de o alfabeto desambiguar graficamente o léxico, sem se fazer valer de recursos do contexto para sua leitura ipsis litteris (leitura verbatim). Esse seria o único sistema de escrita que permitiria a leitura verbatim. Essa qualidade não se encontraria em sistemas ideográficos, logográficos ou alguns casos de sistemas silábicos, que teriam que fazer uso do contexto para sua interpretação lexical.

Os autores do modelo autônomo contemplaram apenas os alfabetos como sendo "escritas completas" (Goody/Watt, 1968). Todos os demais sistemas de escrita eram considerados casos de letramento restrito. Para Goody, as escritas não-alfabéticas foram consideradas formas homeostáticas de transmissão cultural.

\section{C) "Texto autônomo" como um estilo de uso da linguagem}

Entre os autores do modelo autônomo, Olson foi o que explorou mais em detalhe as diferenças lingüísticas entre oralidade e escrita 
através da proposta de distinção entre "texto autônomo" e "enunciado". Cada um deles corresponderia a diferentes estilos de linguagem e diferentes modos de comunicação. O enunciado teria como situação prototípica uma conversa informal, enquanto o texto autônomo estaria representado pelos textos científicos e religiosos.

A oposição entre enunciado e texto autônomo em Olson é derivada da proposta da Pragmática de diferenciar "sentido da sentença" (texto autônomo), e "sentido do falante" (enunciado). Esta distinção parte da suposição de que na oralidade o sentido é dirigido pragmaticamente, acompanhado por gestos, sons e contexto. Tudo isso leva a particularizar o sentido denotativo e conotativo. O significado é compartilhado entre as intenções do falante e do ouvinte.

No texto autônomo, o significado está convencionalizado na sentença e é derivado exclusiva e completamente pelos elementos lexicais e pela ordem sintática. Ele representaria um estilo de uso da linguagem, que procura a explicitação do sentido exclusivamente pelo texto escrito, sem fazer referência a informações contextuais para sua compreensão.

A distinção entre enunciado e texto autônomo teria uma dimensão histórica. Para Olson, haveria uma transição entre enunciado e texto autônomo na história da humanidade e do indivíduo. Enquanto o enunciado oral seria uma modalidade universal, o "texto autônomo" estaria restrito culturalmente às sociedades com escritas alfabéticas-tipográficas.

O desenvolvimento da idéia do texto autônomo teria sido possível com a invenção do alfabeto grego, que permitiu uma leitura verbatim, independente do contexto para sua decodificação, ao contrário da escrita semítica que requeria um conhecimento contextual para desambiguar a escrita. O traço desambiguador deste sistema de escrita teria surgido historicamente com a distinção de vogais e consoantes na formação do alfabeto grego, permitindo manter o léxico diferenciado graficamente e evitando ambigüidades presentes em possíveis heterófonos (sons diferentes e grafias iguais).

Um segundo momento relevante na formação do estilo literário de texto autônomo, segundo Olson, foi com o surgimento da 
imprensa, quando se desenvolveu a idéia de que um texto escrito tem apenas uma interpretação possível. Surge a idéia de que a sentença deve ter apenas um sentido. Esta visão está presente no protestantismo e na ciência. No protestantismo, ela está presente na posição defendida por Lutero de que o texto é seu próprio intérprete (Olson, 1991a:153). Esta postura ocasionou uma separação entre o texto dado e a interpretação do texto, tornando inválida a visão de que escribas e clérigos teriam a melhor interpretação. No domínio da ciência, o texto autônomo surge a partir da separação entre observação da natureza e interpretação do fato observado.

O surgimento do "texto autônomo", portanto, ocorre concomitante à diferenciação de um texto escrito de sua interpretação. No âmbito religioso, isto significa que o estatuto de heresia surge paralelamente à fixação de um texto pela escrita. Não haveria, em religiões orais, a idéia de ortodoxia. Esse seria um fenômeno próprio das religiões baseadas na figura do livro.

\section{2 - A negação da autonomia}

O termo "modelo ideológico da escrita" identifica um grupo de autores - Brian Street, S. Scribner, Michael Cole, Shirley Brice Heath, David Barton entre outros - que puseram em discussão a atribuição do valor de autonomia para a escrita. O termo ideológico, nesse caso, estaria se opondo à visão de neutralidade atribuída à escrita no modelo autônomo e estabeleceria, por sua vez, o vínculo entre escrita e relações sociais. Em Street (1995), principal proponente do modelo ideológico, o valor de autonomia é abandonado como definição da forma de funcionamento da escrita e ganha o status de um mito.

As críticas do modelo ideológico à idéia de autonomia da escrita são: 


\section{A) Impossibilidade de se fazer generalizações sobre escrita ou oralidade}

Uma das críticas de Street (1995) ao modelo autônomo da escrita é a sua postura de assumir os efeitos da escrita como idênticos em todas sociedades, sem atentar para o que os grupos fazem efetivamente com a escrita. Essa crítica retira qualquer possibilidade de se fazer generalizações a respeito das tecnologias de comunicação, que foram o ponto de partida do modelo autônomo, influenciado pelos trabalhos do historiador Harold Innis e do filósofo M. McLuhan. A proposta do modelo ideológico é, ao contrário, apontar a variedade de formas de uso da escrita de uma comunidade para outra, ou ainda no interior de uma mesma comunidade. Muitos desses usos se mostram diferentes daqueles caracterizados pelo modelo autônomo, onde a escrita era definida como linguagem descontextualizada, nãoambígua, independente do oral e usada como forma de adquirir conhecimento, etc.

A ênfase na diversidade de experiências de escrita surgiu quando o foco das análises dos autores do modelo ideológico saiu do domínio da escola, da ciência ou ainda do mundo ocidental. Street (1984), por exemplo, estudou o uso da escrita para fins comerciais em comunidades agrícolas no Irã. Scribner e Cole (1981) trabalharam na Libéria entre os Vai, que utilizam três sistemas de escritas (o silabário Vai, a escrita árabe e a escrita alfabética em inglês). Shirley Brice Heath (1990) estudou algumas comunidades nos Estados Unidos e mostrou como os hábitos de escrita dessas comunidades diferiam daqueles promovidos pela escola. David Barton e Padmore (1991) pesquisaram a escrita de uso doméstico numa cidade inglesa, entre uma parcela da população considerada pelos planos educacionais do governo como tendo defasagem no uso da escrita.

Em comum, esses trabalhos analisaram a distância entre os hábitos cotidianos de escrita e aqueles privilegiados pela escola. Com esses estudos, eles quiseram dar visibilidade a usos não contemplados pelo modelo autônomo. 


\section{B) Crítica ao conceito de escrita restrita (restrict literacy)}

A posição do modelo autônomo de definir a escrita apenas nos ambientes da escola e da academia - os únicos considerados como full writing - teve como conseqüência tornar todas as outras formas de uso como de caráter restrito ou apenas formas embrionárias de escrita, sem terem alcançado um uso completo. Uma conseqüência dessa posição foi a não-avaliação das habilidades presentes fora da escola e a não-verificação do seu papel e função, ou as aspirações e valores associados a estes usos.

A crítica à autonomia levou a considerar que a categoria de escrita restrita tinha um forte caráter etnocêntrico.

\section{C) Interconexão da escrita e da oralidade}

Um ponto criticado pelo modelo ideológico é a noção de polaridade (the great divide) entre escrita e oralidade, pressuposto este que seria responsável pela definição da escrita como autônoma e sua existência como independente da oralidade.

Uma fonte de crítica à polaridade entre escrita e oralidade pode ser tomada da história das religiões. William Graham (1987) aponta a relevância da oralidade no domínio das religiões de Escritura, ao mostrar que o status de texto sagrado surge de diversas práticas sociais que as envolvem. Ele analisa várias práticas orais presentes em religiões de Escritura (protestantismo, judaísmo e islamismo). As religiões de Escritura não podem ser reduzidas apenas ao texto escrito em sua forma de religiosidade (como enfatiza o modelo de Goody), mas é antes de tudo uma experiência humana que combina várias outras dimensões sensoriais (olhar, tocar, ouvir, etc.) (Graham, 1987: 6). Ainda que a escrita tenha servido para preservar o texto religioso como texto com status autônomo, a influência e a difusão do texto ocorrem através de formas de pregações e ensinamentos orais.

Outra via de rompimento com a idéia de polaridade entre escrita e oralidade se deu através do conceito de evento literário, proposto por Brice Heath (1990). Eventos literários seriam situaç̧ões comunica- 
tivas que incluem algum tipo de texto escrito como parte da interação entre os participantes. Exemplos de evento literário no domínio acadêmico - considerado a seara do "texto autônomo" - são os seminários e cursos, que apontam para a interconexão do texto científico com a oralidade. A importância do conceito de evento literário é poder mostrar a articulação entre escrita e oralidade, que permaneciam separadas no modelo anterior.

O conceito de evento literário tem sua origem na concepção de evento comunicativo (ou de fala), proposto pela etnografia da comunicação de Dell Hymes. O específico do evento literário é representar situações comunicativas nas quais se faz uso de um texto escrito como parte da interação. A análise focaliza um evento no qual a escrita tem um valor importante e procura relacioná-lo com as características sociais do seu contexto de uso. São essas características que configurariam a natureza da escrita nesta situação. Nesse caso, a escrita terá seu sentido derivado do contexto maior (Besnier 1995:9).

A metodologia de trabalho com um evento literário é descrever os participantes, as formas como ocorrem os turnos, o domínio institucional, as atitudes e valores. Os eventos literários são ainda passíveis de uma análise histórica que situe seu lugar no passado e suas transformações.

Brice Heath (1990) utilizou o conceito de evento literário em uma pesquisa que procurava descrever as formas em que as crianças eram socializadas na comunicação oral e escrita em suas comunidades e como estes comportamentos se diferenciavam da prática escolar. Um evento de fala analisado por Brice Heath foi o de contar histórias para crianças na hora de dormir através da leitura de livros infantis. Sua relevância enquanto evento literário é o de representar uma forma de socialização da criança ao estilo do texto autônomo antes de entrarem na escola. Cada comunidade apresentava diferentes hábitos de leitura nesse contexto. Em uma delas não havia essa situação de leitura, em duas outras, que a possuíam, os adultos se comportavam diferentemente em relação ao texto lido. Em uma das comunidades, as crianças deveriam se restringir ao que estava no 
texto, em outra, a criança era convidada a acrescentar criativamente elementos à história.

A análise de Brice Heath apontou que os hábitos de fala e escrita nas comunidades eram diferentes daqueles propostos pela escola. Muitas das situações presentes na escola - como dar rótulos aos objetos, recontar uma história ou criar uma narrativa - poderiam não ter os mesmos valores nessas comunidades ou então não se apresentariam nesta ordem.

\section{3 - PROPOSTA DE ANÁLISE DO VALOR DE AUTONOMIA NA ESCRITA MISSIONÁRIA}

$\mathrm{Na}$ análise da escrita missionária evangélica, o interesse será conservar o polêmico conceito de texto autônomo, porém sem lhe atribuir o valor de uma qualidade geral da escrita alfabética, ou vêlo independente da oralidade, que são algumas das críticas que o modelo ideológico lhe faz. A proposta será tratar texto autônomo como um tipo ideal instituído pela análise, como forma de dar conta da especificidade histórica dessa tradição evangélica de escrita.

Enquanto tipo ideal, não se está dando ao texto autônomo o caráter de um fato da realidade. Ele é um produto da análise ao procurar dar realce a alguns fatores e deixar à margem outros. A acentuação do traço de autonomia na análise da escrita missionária evangélica permitiria dar conta da presença da concepção de sentido literal e de texto único presente nessa tradição de escrita.

A suposição da análise será que a idéia de sentido literal está regida por valores e racionalidades associados à escrita autônoma. Sentido literal viria a ser o que se faz com a escrita. Quando se fala do literal, exemplifica-se com as condições da escrita autônoma. Seguir essa direção representaria uma visão não essencialista do sentido literal, ao não considerá-lo como uma característica geral da linguagem, e condicioná-lo a um jogo de linguagem específico, o da escrita na tradição ocidental.

Tomar a escrita autônoma como expressão da idéia de sentido literal é uma sugestão retirada do texto clássico de Olson (1991a) e, 
em particular, de um artigo de Rommetveit (1988), que aborda a presença do viés da escrita na concepção de linguagem dos semanticistas. Para Rommetveit é importante conservar a perspectiva do sentido literal mesmo quando se suponha que a linguagem seja heterogênea.

"The point of departure for my reflections on written language biases within various branches of semantics is a position from which embeddedness of linguistic meaning in social interaction acquires a particular saliency. Such an outlook, of course, implies a definite bias against general paradigms aiming at explanatory accounts of human intersubjectivity exclusively or primarily in terms of invariant features of the linguistic medium as such. The myth of literal meaning, however, cannot be discarded as a mere illusion within such a social-cognitive perspective. Myths are not only "stories told" but also "realities lived" (Malinowski, 1984), i.e. they are social realities and of considerable theoretical interest as such. And the myth of literal meaning, I shall argue, is in our highly literate societies a reality lived by enlightened laymen under subtle influence from stories told by prominent scholars of semantics" (Rommetveit 1988:15)

No contexto do SIL, sentido literal faz parte da realidade social vivida pelos seus membros, configurando-se como uma ideologia presente na formação do missionário. A importância do conceito de sentido literal em uma análise sobre o SIL é por ela ser uma missão fundamentalista que segue uma interpretação literalista da Bíblia. Esta postura religiosa se opõe a tomar o texto bíblico como uma alegoria, na qual se atribui ao texto um significado diferente do que o dito.

Nos manuais de tradução do SIL dirigidos aos missionários, manter-se fiel à tradução representa transmitir uma "interpretação literal da Bíblia" (Beekman \& Callow, 1974:20). Esta posição leva, por exemplo, a excluir as metáforas, transformando-as em sentido explícito, nas traduções para as línguas indígenas (Barnwell, 1979).

A noção de sentido literal está presente tanto na forma de religiosidade do SIL como na lingüística utilizada pela missão. A noção de sentido literal na religião e na lingüistica tem em comum: 
i) privilegiar a unidade como concepção de linguagem, em oposição à sua caracterização como heterogênea; ii) apontar para a determinação dos sentidos a partir das formas lingüísticas, em oposição à idéia da sua indeterminabilidade.

Em que pesem as semelhanças entre as noções de sentido literal, religioso e científico, elas são estipuladas de diferentes maneiras nesses dois domínios. No contexto religioso, a unidade da Bíblia está assegurada pelo seu estatuto de texto revelado pelo Espírito Santo, o que assegura a existência de um ponto fixo - o texto original na maneira em que foi escrito por seus autores sob inspiração divina -, e que deve ser referência de sua compreensão fidedigna.

$\mathrm{Na}$ Lingüística, a literalidade representa a possibilidade de determinar o sentido de toda expressão lingüística, independentemente do seu contexto de uso, por meio de uma análise componencial. Por meio deste tipo de análise, o sentido de uma sentença-tipo é postulado a partir do sentido de cada uma das suas partes (seus constituintes) e da ordem linear dos seus componentes. A tese da literalidade faz equivaler a análise componencial com o processo interno de compreensão do falante.

A tese do sentido literal na Lingüística está presente também no conceito de "tipo lingüístico", que postula a existência de um nível de semelhanças entre enunciados usados em diferentes contextos. O pressuposto sobre o qual se define tipo é a existência de uma relação determinada e invariante entre forma e sentido (Lyons 1972).

O conceito de texto autônomo, enquanto expressão de sentido literal religioso, será articulado a dois níveis de análise da escrita missionária:

a) uma análise histórica que aponte os traços de texto autônomo da escrita missionária (macroanálise).

b) uma análise sociolingüística que aponte a socialização do traço de texto autônomo pela oralidade através da interação entre missionário e falante nativo (microanálise). 
O objetivo da dupla análise é relacionar a história da tradição evangélica de escrita (macroanálise) a uma prática de uso relevante dessa tradição de escrita através da descrição de uma situação de leitura (microanálise). Esta última refletiria as características apontadas ao nível macro dessa tradição de escrita.

\section{1 - Texto autônomo em uma análise histórica da escrita missionária}

A proposta é fazer uma história intelectual do modelo de escrita missionária evangélica através da análise da presença do conceito de escrita autônoma. Este conceito servirá para caracterizar o modelo de escrita idealizado pela política evangélica de tradução bíblica

Texto autônomo, enquanto expressão de sentido literal no contexto missionário, será definido como um modelo cultural específico de escrita. Ele será tomado como um padrão cultural de escrita da tradição ocidental, conformado por um determinado conjunto de valores e práticas de escrita:

i) predomínio do livro como modo de comunicação autônoma: o livro é considerado por si só capaz de comunicar independentemente de estar inserido em um contexto de uso;

ii) leitura silenciosa: a leitura, definida como um modo de comunicação autônoma, privilegiaria a leitura silenciosa como situação definidora do que é ler;

iii) leitura verbatim: ela reproduziria ipsis litteris o texto quando lido através do uso do sistema de escrita alfabético;

iv) a fonologia como modelo ortográfico: este modelo de alfabeto eliminaria heterófonos através da regra "para cada fonema um só grafema" e a metodologia do "par mínimo" (procurar itens lexicais que se distinguem por um som). Haveria nesse padrão de escrita uma relação entre sentido literal e sistema de escrita alfabéticotipográfico latino. 
Desta forma, o status de escrita autônoma se conformaria de situações específicas de uso da escrita, que ganham o status de ideais. Não há nelas nenhum traço de generalidade, apenas enquanto valoracão que lhes é atribuída como tal.

Em suma, texto autônomo será analisado como uma concepção de escrita historicamente localizada no movimento religioso de tradução bíblica desencadeado no início do século XIX na Inglaterra e nos Estados Unidos, com repercussões na forma de atuação das missões.

Nessa análise histórica, as diferentes iniciativas de elaboração de escritas em línguas indígenas por diferentes missões em distintas regiões serão tomadas como parte de uma mesma campanha de alfabetização por terem se originado de um mesmo ideário e de uma mesma tradição de escrita. A pesquisa está assumindo, portanto, uma continuidade entre os diferentes projetos missionários evangélicos que atuaram pela tradução bíblica. Eles estariam vinculados a uma tradição comum que tem sua origem na reforma protestante. A continuidade será tomada como um instrumento analítico que representa assumir uma mesma pergunta que se faz a diferentes épocas e lugares (Graff 1986:73). No caso da escrita missionária, uma questão comum que se está assumindo é a postulação do texto bíblico traduzido como texto autônomo.

O conceito de campanha de alfabetização é definido nos estudos de história da escrita como movimento para promover massivo e rápido aumento do alfabetismo (Arnove/Graff, 1987). As campanhas de alfabetização estão associadas ao interesse de autoridades centralizadas estabelecerem um consenso, seja moral ou político, ou para construir uma nação. Um dos papéis das campanhas é integrar indivíduos em uma comunidade, seja política ou religiosa. É nesta última caracterização que parece interessante analisar as campanhas evangélicas de alfabetização como parte do processo de incorporação do indivíduo a uma nova comunidade (a evangélica). 


\section{2 - Texto autônomo em uma análise sociolingüística da escrita missionária}

A proposta é procurar a idéia de texto autônomo em situações comunicativas. Desta maneira, texto autônomo não será tomado como um conceito independente da oralidade, mas conectado a esta.

A análise sociolingüística enfocará uma situação particular de leitura no contexto missionário, que reflete as características dessa tradição de escrita. Observar a leitura como um evento literário significa procurar as formas sociais de seu aprendizado e seu emprego em uma comunidade. A pessoa não aprende apenas a decodificar e codificar, mas aprende também como utilizar essas habilidades nos contextos sociais. A leitura será analisada como uma prática modelada diferentemente em cada grupo e contexto, em oposição a tratá-la como uma habilidade homogênea de decodificar sinais gráficos em todas as situações que ocorra. Para o livro Ethnography of reading, organizado por Boyarin (1992), não haveria uma noção simples de ler como uma tecnologia ou prática independente de qualquer contexto social.

As raízes sociais da leitura estariam presentes mesmo na modalidade da leitura individual e isolada, pois, ainda nesse contexto, o leitor estaria reproduzindo as formas de leitura em que ele foi socializado em relação ao que ele deve ler, para que propósitos, em que contextos e como interpretar o texto.

O evento literário escolhido no contexto da escrita missionária é uma situação de diálogo entre o missionário e o ajudante de tradução nativo a respeito de uma passagem bíblica traduzida, que inclui uma situação de leitura (comprehension check). Ele será enfocado como um exemplo da concepção e prática de leitura no interior das missões e uma situação de aprendizado do traço de autonomia da escrita. Este evento literário aponta a importância da oralidade na formação da idéia da escrita como autônoma.

O comprehension check será tomado como uma situação de construção do sentido literal religioso. Ele é uma situação comunicativa na qual se ensina ao falante nativo a ser convertido a leitura literal do texto bíblico. 


\section{4 - O MOVIMENTO MISSIONÁRIO DE TRADUÇÃO BÍBLICA COMO UM MODELO DE ESCRITA}

"[the] sole object [of the British and Foreign Bible Society] shall be to encourage a wider circulation of the Holy Scriptures [...] without Note or Comment" (Regulamento da BFBS apud Smalley 1984:62)

O movimento de tradução bíblica surgiu no início do século XIX no mundo protestante europeu e americano como uma manifestação religiosa centrada na distribuição universal da Bíblia. Sua proposta era tornar a Bíblia impressa acessível em todas as línguas e em diferentes sistemas de escritas. Nesse movimento religioso, a expansão do mundo evangélico se expressava pela quantidade de Bíblias, completas ou parciais, vendidas ou pelo número de línguas com traduções bíblicas.

A dimensão que esse movimento religioso teve pode ser constatada pelo número de línguas que tiveram textos bíblicos impressos nesse período: enquanto entre 1400-1700 foram 42, no século XIX, foram mais de 400 (Smalley, 1984:34). Esse número parece pequeno se for comparado à cifra de 200 novas línguas ou variantes dialetais que tiveram textos bíblicos traduzidos entre 1990-96 (UBS 1997).

Esse movimento religioso centrado em torno da figura do livro sagrado surgiu imbricado a um modelo de escrita, que expressava suas principais idéias religiosas. As concepções do que é ser fiel ao texto bíblico em uma tradução ou a do que é ser cristão, por exemplo, estavam relacionadas a um modelo de escrita. A atenção dessa seção será apontar algumas características da concepção de escrita presente no movimento de tradução bíblica, em especial, suas atividades projetadas para comunidades com línguas ágrafas

O movimento de tradução bíblica iniciado no século XIX apresentou situações distintas daquele que ocorreu durante a Reforma Protestante. Enquanto Wycliffe, no século XV, ou Lutero, no século XVI, propuseram traduções bíblicas enquanto falantes nativos e o fizeram enquanto parte de uma dissidência religiosa no interior do Cristianismo, as traduções produzidas a partir do século XIX são 
iniciativas do não-falante nativo e fazem parte de uma modalidade de conversão ao Cristianismo. A tradução bíblica se tornou um processo de tradução institucional, para o qual se requer autorização para sua impressão por parte de instâncias superiores (missões e sociedades bíblicas). A última palavra para autorizar sua impressão transcende à comunidade dos falantes nativos.

As traduções para línguas ágrafas envolveram missões e sociedades bíblicas. No século XIX, as missões se apresentavam como extensões diretas de Igrejas denominacionais e não aparecem ainda com o estatuto de "missão de fé" (independente de uma igreja) como no caso do Summer Institute of Linguistics.

As sociedades bíblicas, por sua vez, eram formadas pela aliança de Igrejas de denominações protestantes diferentes com o fim de distribuir massivamente a Bíblia impressa. A primeira a ser criada e, que se tornou modelo para as demais, foi a British and Foreign Bible Society (BFBS) em 1804 na Inglaterra. As sociedades bíblicas foram importantes como centralizadoras e difusoras desse modelo de ação missionária. Seu papel era gerir e autorizar as publicações das traduções e estabelecer a ligação entre o tradutor e o impressor. Através de documentos que expunham as regras a serem seguidas na tradução e na publicação dos textos bíblicos (Girdlestone, 1877/ Morris, 1901/BFBS, 1925/ABS, 1932), as sociedades bíblicas tiveram ingerência no tipo de modelo ortográfico a ser utilizado e no padrão editorial a ser seguido.

A relação entre missões e sociedades bíblicas se dava pelo apoio financeiro que estas poderiam dar a algum estágio da produção de uma tradução ou de sua posterior impressão.

"Yet Bible work has not been commited to missionaries alone. The Churches have combined to establish Bible Societies to assist and sustain this department of Christian effort. It is the province of these societies to suggest the setting apart of a well-qualified man for the preparation of a version, and on its completion to bear the expense of printing it and to grant liberal supplies to the mission where it will be used." (Reed 1879:1) 
A BFBS definia sua atuação através de quatro figuras: o tradutor, o impressor, o vendedor de Bíblias (colporteur) e a mulherleitora (Biblewoman), que conformavam uma rede de funções e ocupações em torno ao livro sagrado. Esta rede abrangia desde a tradução até o ensino da forma correta de ler o texto bíblico.

O conceito de texto autônomo é útil para analisar esse modelo de escrita baseado nas seguintes características: a) na figura do livro sagrado; b) na definição funcional de alfabetizado como sendo saber ler a Bíblia; c) na concepção do texto bíblico organizado por parágrafos; d) e, finalmente, no predomínio do emprego do sistema de escrita alfabético romano em versão tipográfica.

\section{A) a ênfase na figura do livro sagrado}

W. Mignollo (1994), em um estudo sobre a introdução da cultura do livro na América colonial em comunidades que empregavam sistemas de escritas não-alfabéticas (azteca, maia e inca), propõe que se analise o livro não enquanto uma classe de objeto que possui uma propriedade essencial, mas como um conjunto de práticas culturais que conformam o seu lugar no grupo. Essa proposta levaria a que se considere, na análise do livro sagrado, o conjunto de regulações e metáforas que estão inscritas no seu uso. Ao seguir essa sugestão na análise do movimento missionário de tradução bíblica, a atenção estará voltada para a descrição de algumas práticas e concepções que circundam o status de livro sagrado nesse contexto.

A figura do livro é uma presença constante na literatura evangélica de arregimentação de missionários e de apoio para as missões; aparece regendo a vida do missionário, justificando sua ida para outras terras e representando, finalmente, o objetivo do seu trabalho de evangelização.

"The true Missionary, to whatever society he may belong, takes with him this book as the charter of his hope; in it he finds the substance of his teaching; this is the test by which he desires that his life-work may be tried; this is the best legacy he can leave when his own voice is hushed" (Reed 1879:1) 
No contexto de comunidades ágrafas, a identidade procurada pelos missionários será a de se apresentar como os "homens do livro" (Nida, 1947:3). Um exemplo da concepção do encontro entre o "homem do livro" com uma sociedade ágrafa pode ser vista na passagem referente a um missionário - no caso um samoano - nas ilhas Niue (Pacífico) (Canton, 1904:55). O missionário é descrito em situação de leitura do livro sagrado, com poder e sem medo frente os perigos, versus homens sem escrita, apresentados sem poder e vivendo sob o medo.

"The fierce men with long wild hair and trappings of manycoloured feathers are held in check by a mysterious fetish - a book which the Samoans carry about with them, to which they speak, which talks to them. At length, two noted braves are sent to slay the strangers. They steal up to the palm-thatched house; they see Paulo sitting quietly reading his book; they wait awhile. He still sits reading with a peaceful face, and a great fear and trembling fall upon them; they are powerless" (Canton 1904: vol.4:13)

No contexto de análise do livro sagrado, o conceito de "texto autônomo" é relevante para representar o seu status de texto único, sem ambigüidades e completo. O valor de autonomia do livro sagrado na estratégia da tradução bíblica está presente no lugar que lhe é atribuído na manutenção de uma Igreja evangélica na ausência dos missionários. Nesta perspectiva, a comunidade evangélica se autosustentaria através da leitura do texto bíblico, como o concebe um missionário entre os Terena.

"It is of the greatest importance to the success and permanence of a work that the converts and their children learn to read the Word of God. A Christian community that is unable to read for itself God's Word must ever remain dependent upon the missionary and could never become self-propagating and selfgoverning" (Hay 1928:78) 


\section{B) Concepção funcional de alfabetizado como saber ler a Bíblia}

Uma característica das campanhas de alfabetização do movimento de tradução bíblica foi a maior importância dada a habilidade de ler do que a de escrever. Um sinal dessa ênfase na leitura era a pouca presença de material para escrever - como lápis, caderno em comparação com a forte presença de imprensas instaladas pelos missionários em várias partes do mundo. Essa ênfase na leitura foi uma característica da alfabetização vinculada a movimentos protestantes, como o ocorrido na Suécia no século XVII, quando saber ler se tornou exigência para todos. Uma pessoa só poderia receber os sacramentos ou casar se dominasse a leitura de textos religiosos (Arnove/Graff, 1987).

As duas definições abaixo do conceito de alfabetização no contexto missionário, uma do século XIX, e outra de uma missionária do SIL, explicitam a ênfase dada à habilidade da leitura centrada em um único texto.

"For universal experience has long taught that it is not sufficient
for the missionaries to learn the language of the natives in order
to introduce Christianity permanently into any country. Only
where the word of God is read by the people themselves, and
where a whole people are made susceptible of the spirit of
Christianity by the distribution of the Bible and of Christian
school-books, can a rapid, deep and lasting work be hoped for"
(Lepsius 1863:26). "literacy is the ability to read the Bible fluently and with understanding" (Gudschinky 1951:1)

A leitura no contexto religioso tem o sentido de obrigação e não de um ato voluntário, diferentemente de uma concepção hedonista da leitura, onde ler tem o papel de instigar as emoções. No domínio religioso, a leitura contém as obrigações que o leitor deve seguir (Boyarin, 1992:10) e está relacionada à obediência. Um exemplo dessa concepção religiosa de leitura é a que está na cartilha Jê de 1959: 
"Agora que vocês saber ler, vão apreciar muitos livros. O melhor livro em todo o Brasil é a Bíblia pois é o livro de Deus [...] Ouvir e obedecer a Ele é o caminho do bem e da felicidade" (B[anner], H. 1959:24)

\title{
C) Parágrafo como forma de organização dos textos bíblicos
}

O movimento de tradução bíblica esteve baseado na concepção do texto bíblico organizado por meio de parágrafos e não por versos, aproximando-se assim do estilo do texto autônomo.

\begin{abstract}
"Inasmuch as the ordinary chapter and verse divisions (which are comparatively modern) are liable to interrupt and obscure the meaning and connection of Holy Scripture, many translators ask that new translations, and revisions of existing translations, be published in paragraph forms, with or without sectional divisions or headings. The Committee do not object to this course where it will not create difficulties by introducing a change of form to which readers are unaccustomed and the value of which they cannot appreciate" (BFBS 1906:10)
\end{abstract}

\section{D) Criação de escritas alfabético-tipográficas}

Até o início do século XX, a BFBS tinha publicado o texto bíblico em cerca de 60 diferentes sistemas de escrita. As tipografias das principais sociedades bíblicas, tais como British and Foreign Bible Society e American Bible Society, estiveram incubidas de produzir soluções técnicas para a passagem de um sistema não-alfabético manuscrito para impresso. Dentro dessa diversidade de emprego de sistemas de escrita, houve o caso da invenção de um silabário para a língua Cree por um missionário no Canadá em 1840 para ser utilizado na tradução de textos religiosos.

Com o passar do tempo, porém, deu-se o predomínio do uso do sistema alfabético romano nas traduções bíblicas. Seu uso não se restringia apenas ao emprego do repertório de letras, mas também dos sinais de pontuação e das regras de uso de letras maiúsculas e 
minúsculas. Essa última distinção gráfica, por exemplo, será considerada importante para delimitar o léxico religioso, que deveria ser escrito por maiúscula. Além de letras e pontuações próprias do sistema alfabético romano, o missionário empregará as unidades gráficas peculiares a esse sistema de escrita, tais como palavra, sentença e parágrafo.

A importância do caráter tipográfico nesse modelo de escrita levou as missões a introduzirem em vários partes do mundo as primeiras imprensas para escritas em línguas ágrafas. Essas escritas são formuladas pela primeira vez sob a égide da imprensa, sem antes terem tido uma história como escrita manuscrita. O fato de essas escritas terem surgido em forma impressa significou que elas foram estabelecidas com maiores exigências de normatização em relação às variações dialetais.

O predomínio do sistema alfabético romano na prática do missionário-tradutor pode ser encontrado nas seguintes situações:

i) Em algumas regiões, os missionários foram defensores da romanizacão das línguas que não seguissem esse sistema de escrita. Esse foi o caso de missionários ingleses na Índia, que participaram dos debates pela romanização das línguas indianas, junto a administradores coloniais (Williams, 1859). Em lugares com influência muçulmana, a proposta era também a romanização.

"In the case of Swahili and other African languages which have Arabic words mixed up with them, and are largely impregnated with Mohammedan modes of expression, the best course appears to be to stick steadily to the Roman and root out the Arabic" (Girdlestone 1877:47)

ii) Uma versão romanizada do texto bíblico poderia ser impressa paralela à publicação do texto em um sistema não-alfabético romano. Nesse caso, o objetivo da versão romanizada era o seu uso pelo não-falante nativo. Esse é o caso de uma publicação de um texto bíblico em bengali fazendo uso do alfabeto romano para ser usado pelos europeus que quisessem ler para seus empregados (King 1900:25). 
iii) por fim, era obrigatório o envio de uma transliteração em escrita alfabética romana para a sociedade bíblica, sempre que o texto bíblico traduzido empregasse outro sistema de escrita (ABS, 1932:16 in Nida, 1947).

O requisito de uma transliteração em alfabeto romano como condição para se conseguir a autorização para publicação indica que o sistema de escrita alfabético romano é a base do critério de fidelidade no mundo missionário. É através desse sistema de escrita que se verifica a fidelidade do texto traduzido.

A preferência pelo sistema alfabético-tipográfico no contexto missionário estaria relacionada à concepção religiosa de sentido literal, por permitir a leitura verbatim e a fixação do texto, que são condições da idéia de literalidade no mundo evangélico.

\section{i) Condição de uma leitura verbatim}

O sistema alfabético permite na leitura uma maior restrição de variação lexical ou morfológica, se comparado ao sistema ideográfico, que não permitiria a reprodução verbatim das mesmas palavras. O alfabeto ideal seria aquele que tivesse como critério máxima explicitude e não-ambigüidade lexical no ato da leitura.

Outro motivo para a ênfase em um sistema de escrita que permita a leitura verbatim é sua possibilidade de uso por parte de um não-falante nativo, que não domina a língua mas domina o sistema de escrita romano. Essa é uma condição necessária ao missionário, um falante estrangeiro.

\section{ii) Texto fixo pelo sistema tipográfico}

A escrita tipográfica torna possível o estabelecimento da figura do "tipo lingüístico", definido pelas características da repetição idêntica. Ele permite a fixação e a estandardização dessa escrita e dessa forma a institucionalização, pela escrita, de sinonímias para o discurso cristão. Estas deixam de ser móveis a cada situação, para serem fixadas. 
A Lingüística vai ter um papel importante, como veremos adiante, na criação de escritas para línguas ágrafas dentro do sistema alfabético-tipográfico. Uma hipótese a ser levantada é que a proporção em que a lingüística foi incorporada à prática missionária, tornou-se mais remoto o uso de outros sistemas de escrita que não o alfabético romano, sendo o caso da invenção de um silabário Cree, como ocorreu em 1840, uma exceção que dificilmente viria a ser repetida como experiência de formulação de uma escrita missionária.

\section{1 - Summer Institute of Linguistics, uma missão de tra- dutores bíblicos na América Latina}

A missão evangélica Summer Institute of Linguistics (SIL), criada na década de 30 no México por missionários americanos, é parte do movimento missionário de tradução bíblica. É hoje a maior missão nesta linha de atuação, ao manter, em 1990, programas de tradução em cerca de 744 línguas, o equivalente a uma população de 70 milhões de pessoas; em 44\% desses programas, a missão foi a responsável pela formulação e difusão de uma primeira escrita alfabética (SIL, 1990).

O título do livro com a história da missão - Two thousand languages to go. The story of the Wycliffe Bible Translators ${ }^{1}$ - (Wallis \& Bennett, 1959) indica que a tradução em novas línguas é a maneira de conceber a expansão das fronteiras do mundo não-evangélico.

A forma de atuação da missão é através da "estratégia da tradução bíblica”, considerada como uma modalidade de evangelização própria para comunidades rurais pequenas, falantes de línguas ágrafas e que conservam o predomínio da comunicação "face a face"(Dye, 1979). Traduzir e ensinar a ler o texto bíblico passam a ser os eixos principais do trabalho missionário do SIL.

"In simplest terms, the translation strategy is an approach to missionary work in which the only formal missionary activity is translating the Bible (or parts of it) into the mother tongue of those being evangelized and teaching them to read it with 
understanding. It emphasizes the vital (though not necessarily exclusive) place of Scripture and the Holy Spirit in making and nurturing believers" (Dye 1979:14)

Uma das particularidades do SIL dentro do movimento de tradução bíblica foi a maneira através da qual adequou a política de evangelização pela tradução bíblica no contexto político da América Latina entre as décadas de 30 e 70 . O resultado dessa política foi a secularização do programa de escrita de origem evangélica na rede de escolas públicas indígenas no continente. Outra particularidade do SIL foi o papel que deu à Lingüística na prática do missionáriotradutor (ver item 5).

\section{A) A identidade de lingüista como parte da estratégia política do SIL na América Latina}

O SIL atuou na América Latina em situações de Estados Nacionais, onde a sua permanência deveria ser negociada localmente. Essa situação será determinante na forma de entrada da missão, que não ocorreu através de alianças com as igrejas evangélicas locais, sem força política nessa época, mas através de alianças com grupos intelectuais nacionais, particularmente os indigenistas.

O indigenismo foi um movimento intelectual presente em vários países da América Latina com diferentes bases teóricas (antropologia no México, positivismo no Brasil e marxismo no Peru), que reivindicava a criação de órgãos oficiais que se encarregariam da parcela indígena da população em substituição às missões católicas, até então, as principais instituições encarregadas dessa população através do instrumento das concordatas.

A política indigenista estabeleceu restrições legais à atuação missionária em vários países da América Latina, mas foi, ao mesmo tempo, a responsável pelo crescimento da atuação missionária evangélica nessa parte do continente. Como o maior enfrentamento do indigenismo, tanto no México como no Brasil, foram as igrejas católicas, houve margem para uma aliança entre indigenismo e 
missões evangélicas, desde que essas últimas atuassem de uma forma não-eclesiástica, caracterizada pela não-atuação pública em atividades religiosas (casar, batizar, etc.).

A estratégia desenvolvida pelo fundador do SIL, W. Cameroun Tonwnsed, foi estabelecer uma missão sintonizada com política indigenista. Townsend e seu grupo, por exemplo, se apresentavam como "indigenistas" (los indigenistas creemos", "a los indigenistas, pues, nos corresponde) (Townsend, 1949:39). A possibilidade dessa aliança entre indigenismo de Estado de caráter anti-clerical e o missionário fundamentalista é tratada por David Stoll (1985) como a chave para entender a penetração posterior do SIL em toda América Latina.

A preocupação por uma identidade pública de caráter nãoreligioso levou o SIL a introduzir seu grupo como lingüistas interessados na análise das línguas indígenas em detrimento da identidade de missionários. Isso levou a uma atuação religiosa de pouca publicidade, ao contrário de uma forte presença pública como lingüistas e alfabetizadores das populações indígenas. Em virtude de a Lingüística ser considerada pelos indigenistas como uma ciência auxiliar na área da educação indígena, a identidade de lingüista permitiu uma maior proximidade dos missionários aos projetos de educação.

A estratégia política assumida na América Latina acabou determinando o organograma da missão, que foi dividida em duas instituições, o SIL e o Wycliffe Bible Translator (WBT), com identidades diferentes. A última se dirigia ao público evangélico e explicitava seus objetivos religiosos. O SIL era a versão para se apresentar no campo, com ênfase na identidade de lingüistas.

\section{B) Secularização do modelo de escrita evangélico}

Outra peculiaridade do SIL foi haver tornado a escola da missão capacitadora da leitura do texto bíblico, no modelo da escola pública para a população indígena em vários países latino-americanos entre as décadas de 30 e 70. O modelo mais acabado dessa presença evangélica na rede de escolas públicas é o caso da Amazônia 
peruana. Desde a década de 50, o SIL foi o responsável pela criação de alfabetos para as línguas da região, pela escolha dos professores (preferencialmente membros da comunidade evangélica no grupo) e pelo seu treinamento na base da missão em Yarinacocha. A missão ainda tem na escola o espaço para difusão do texto bíblico como matéria escolar, alocada na disciplina de moral e civismo.

Se o modelo de secularização da escrita evangélica no interior das escolas públicas teve pleno êxito no Peru, o início dessa prática se deu no México, na década de 30, quando teve início o programa de "educação socialista" de Lázaro Cardenas, que se caracterizou por uma política de criação de escolas públicas separadas da educação religiosa.

A estratégia do SIL foi de moldar o seu projeto missionário de tradução bíblica aos projetos educacionais dos seus aliados, os indigenistas. A posição dos indigenistas em relação à educação indígena era que esta fosse diferenciada da educação rural; sua especificidade estaria no uso oral da língua indígena na sala de aula. A influência da missão nos programas de educação indígena desta época foi a inclusão da alfabetização na língua indígena e não em espanhol.

A primeira participação do SIL em um programa de educação do governo foi no Projeto Tarasco em 1939, do qual participaram também representantes do Linguistic Society of América (Morris Swadesh e Norman McQuown). O fonema foi o padrão de letra nesse projeto piloto de educação indígena.

Uma genealogia do conceito de fonema utilizado pelo SIL tem como referência Sapir e Morris Swadesh, que deram ao fonema uma definição psicológica. A concepção psicológica do fonema terá um importante papel na argumentação do SIL em defesa da alfabetização nas línguas indígenas como programa oficial das escolas públicas indígenas nos países da América Latina. Essa definição do conceito sustentará um discurso a respeito da "naturalidade" do novo programa de educação. Por essa definição, a escrita de base fonológica ganhou um caráter "natural", quando empregada numa 
comunidade ágrafa, por ser considerada um retrato das estruturas mentais do falante nativo de uma determinada língua.

A partir dessa aliança com o indigenismo mexicano foi possível, em diferentes fóruns, a oficialização do programa de alfabetização nas línguas indígenas como modelo das escolas públicas. Um dos primeiros lugares em que isso ocorreu foi na reunião de fundação do Instituto Indigenista Interamericano (III) em 1940, organizada pelo México com a participação dos demais países do continente.

O III representou o salvo-conduto para o SIL entrar nos países da América Latina. Até a década de 70, o III, através dos seus periódicos América Indígena e Boletim Indigenista e seus congressos regulares, foi o principal fórum que o SIL teve para difundir seu modelo de educação por toda a América Latina. William Cameron Townsend participou em vários congressos do III como membro das delegações oficiais e foi por meio desses encontros que a missão oferecia seus serviços de educação a vários países latino-americanos, como por exemplo, Peru, Bolívia, Brasil e Colômbia.

\section{2 - O SIL no Brasil (1956-1972)}

Segundo os arquivos da ABS e da BFBS, as línguas indígenas no Brasil que tiveram algum trecho de texto bíblico traduzido antes da chegada do SIL, na década de 50, foram Tembé (1929), Guajajara (1930), Bororo (1937), Terena (década de 40). Porém, essas experiências de escritas missionárias estiveram limitadas ao domínio das missões, sem repercussão no sistema de escolas indígenas do Serviço de Proteção ao Índio (SPI). Não havia chegado ainda ao Brasil o padrão de secularização da escrita missionária no âmbito das escolas públicas em áreas indígenas.

A primeira vez que esse modelo de educação foi proposto no Brasil foi em 1943, quando a New Tribes ofereceu ao Serviço de Proteção aos Índios a implantação de um programa de alfabetização nas línguas indígenas associado à tradução do Novo Testamento, que contaria com a participação de cerca de 100 missionários. A proposta 
fazia referência ao programa de educação indígena do México nos anos 30 (Freire, 1990:172).

Em 1954, há um novo oferecimento no Brasil de alfabetização nas línguas indígenas, dessa vez pelo próprio SIL, durante uma reunião do III na Bolívia. Ali, Townsend ofereceu à delegação do Serviço de Proteção ao Índio (SPI), presente à reunião, os serviços da missão na área da alfabetização nas línguas indígenas (Hefley \& Hefley, 1974; Oliveira, 1981).

Nos dois oferecimentos, houve recusa por parte do indigenismo brasileiro. Na década de 40, Cândido Rondon, então presidente do Conselho Nacional de Proteção aos Índios (CNPI) e mentor do indigenismo brasileiro, recusou a proposta da New Tribes por considerar que a educação dos indígenas deveria permanecer nas mãos dos órgãos oficiais e não, de estrangeiros (Freire, 1990:174).

A resposta negativa ao oferecimento do SIL nos anos 50, além de ser encontrada em depoimentos de membros da comitiva do SPI (Oliveira, 1981), pode ser encontrada também nos relatórios anuais do SPI desse período. Nesses documentos, a educação bilíngüe era mencionada como desaconselhada pela "equipe de etnólogos", devido à existência de uma enorme diversidade de línguas no Brasil, faladas às vezes por uma centena de pessoas, à inexistência de material disponível sobre essas línguas (gramáticas e alfabetos) e às dificuldades na preparação de professores (SPI, 1954:28). A alfabetização só teria interesse para grupos mais aculturados, e para estes, sendo já na maior parte das vezes bilíngües, não haveria interesse de serem alfabetizados em língua indígena.

Como não conseguiu entrar no Brasil através de propostas de alfabetização nas línguas indígenas, o SIL obteve permissão para entrar, em 1956, através de um convênio com o Museu Nacional, com o oferecimento de pesquisar línguas indígenas sob o enfoque lingüístico. A legitimidade da Lingüística entre setores intelectuais foi a forma de sustentação inicial da missão no país, tendo sido seus membros identificados como "discípulos" da Escola de Boas (Câmara, 1977:65). A utilidade do convênio para a missão foi a de conseguir permissão junto ao SPI para entrar nas áreas indígenas. 
Os antropólogos, parceiros do SIL no convênio com o Museu Nacional, se interessaram por uma escrita de base lingüística para documentar o "último falante" nas línguas indígenas, mas não para ser usada na escola. A falta de interesse da academia pela Lingüística aplicada é possível de ser observada na maneira em que estão pensadas as fases de uma pesquisa lingüística no convênio assinado pelo Museu Nacional e o SIL (1965). O tópico sobre Lingüística Aplicada à educação era a última fase do trabalho. Só depois de documentada, analisada fonológica e gramaticalmente e tendo organizado dicionários, a pesquisa se voltaria para questões aplicadas.

Entre a década de 50 e 70, a atuação do SIL no Brasil na área de alfabetização na língua indígena se deu através de experiências dispersas com o objetivo de divulgar seu programa de educação. A oficialização do programa de alfabetização nas línguas indígenas com base na Lingüística ocorreu em 1972 através de uma portaria da FUNAI. Ela se deu um mês antes da reunião do Instituto Indigenista Interamericano em Brasília, onde os membros do SIL participaram como observadores de várias delegações (México, Brasil, Bolívia, Colômbia, Equador e Suriname) (III, 1972).

Através da portaria da FUNAI de 72, a Lingüística foi oficializada como base teórica deste modelo educacional. A regra a ser seguida na criação dos alfabetos para as escolas seria "para cada fonema, um único símbolo" (FUNAI, Portaria n.75 de 6/7/72 ). O lingüista (o do SIL) era a figura principal dessa escola indígena, e não mais o pedagogo ou o antropólogo.

Uma mudança de concepção em relação a quem deve orientar a educação indígena pode ser observada através da comparação do relatório do SPI na década de 50 (antes da chegada do SIL), com a maneira pela qual a Fundação Nacional do Índio (FUNAI), órgão substituto do SPI, identifica, depois de 70, quem deve ser a figura central da escola indígena. No SPI, era solicitada a presença de pedagogo na discussão de uma escola indígena (SPI, 1953 e 1954). Na escola bilíngüe da FUNAI, requer-se um lingüista, mais exatamente o missionário do SIL. 


\section{5 - LINGÜÍSTICA COMO MODELO MISSIONÁRIO DE ESCRITA AUTÔNOMA}

\section{1 - Institucionalização da Lingüística no domínio missio- nário (séculos XIX-XX)}

"An intimate relation exists between linguistic science and Missionary labours” (Lepsius 1863:1)

No século XIX, a Lingüística entrou no domínio das missões como modelo para formulação de escritas alfabéticas para línguas ágrafas. Inicialmente, o lingüista era alguém de fora da missão, convidado para opinar em questões ortográficas. Esse foi o caso da participação do alemão Richard Lepsius na proposição de um alfabeto standard com base lingüística a convite da Church Missionary Society (Inglaterra) em 1863. A proposta foi publicada no livro Standard Alphabet for reducing unwritten languages and foreign graphic systems to a uniform orthography in European letters, apoiado no prefácio por uma série de missões.

Por volta de 1932, o lingüista continua sendo um especialista de fora da missão, como se pode ver no documento Guide for translators da ABS (1932), onde a instituição se dispunha a fazer contatos com autoridades em Lingüística para auxiliar o tradutor bíblico na questão da formulação de uma ortografia.

A relação entre lingüística e missão se tornou mais estreita com a criação do Summer Institute of Linguistics (SIL) em 1936, quando a disciplina se tornou indispensável na carreira de um missionáriotradutor. Ao contrário da exigência anterior de que o tradutor bíblico tivesse conhecimento do grego, o SIL abria mão desse conhecimento, mas não de que o tradutor soubesse Lingüística (PIKE, E., 1981:50). Dessa experiência surgiu o missionário-lingüista, um evangélico que passa obrigatoriamente por cursos de Lingüística no momento em que se decide pela vida de missionário.

"The translator cannot neglect any part of descriptive linguistic studies if he is to make an adequate translation" (Nida, 1947:62). 
Um fator determinante para a institucionalização da Lingüística no SIL foi certamente o contexto político-intelectual do México na década de 30, quando a identidade pública escolhida por aquele grupo de tradutores bíblicos foi a de lingüistas, para contornar restrições legais a missionários. A identidade de lingüista não foi apenas um passe para entrar no país, mais também favorecia a participação dos missionários nos programas oficiais de educação indígena, possibilitando direcioná-los para as exigências da tradução bíblica, que era o da alfabetização em língua indígena.

Porém, a Lingüística não foi apenas uma identidade assumida para o público externo como parte de uma estratégia política; ela se tornou uma concepção de linguagem internalizada em várias instâncias da prática do missionário. Além do uso tradicional da Lingüística como modelo de ortografia, a disciplina foi absorvida no SIL em questões envolvendo tradução bíblica (Nida, 1947) e repercutindo nas noções religiosas de fidelidade e literalidade.

Depois do SIL, outras missões evangélicas no Brasil incorporaram o termo lingüistica como parte de seus nomes, tal como Instituto Lingüístico Ebenezer e Associação Lingüística Evangélica Missionária (ALEM).

Uma explicação para esta "relação íntima" entre Lingüística e missão pode ser encontrada na análise epistemológica da Lingüística que fazem Roy Harris (1980) e Linell (s.d), para quem a ciência da linguagem constrói um modelo de análise da oralidade através de conceitos e categorias tomados da tradição alfabético-tipográfica.

\section{"[...] modern linguistic theory, including psycholinguistics and sociolinguistics, approaches the structures and mechanisms of spoken language with a conceptual apparatus, which - upon closer scrutiny - turns out to be more apt for written language in surprisingly many and fundamental aspects. I will refer to this situation as the written language bias in linguistics" (Linell s.d.1)}

Uma forma de presença do sistema de escrita alfabéticotipográfico na Lingüística estaria na formação do conceito de "tipo" lingüístico, definido pelas qualidades da escrita autônoma (descon- 
textualizado, fixo, único, repetível). Um exemplo de tipo lingüístico é o conceito de sentença, no qual se considera apenas a semelhança dos elementos lexicais e sua ordem no enunciado. O critério que define sentença é a semelhança das formas lingüísticas, independentemente de que as mesmas se apresentem como diferentes atos ilocutivos.

Outra manifestação do caráter alfabético da Lingüística está presente quando se toma a representação ortográfica standard como identificadora das principais unidades lingüísticas (fonema, léxico, sentença). Em todos elas, o dado lingüístico é construído dentro das regras normativas da escrita alfabética, como a de assinalar uma letra para cada som, a de dar importância à ordem linear no papel e a de manter o espaço em branco entre segmentos.

A natureza alfabético-tipográfica do conhecimento lingüístico tornou essa ciência, no interior das missões evangélicas, um modelo completo de escrita autônoma para ser usado na elaboração de ortografias para línguas ágrafas, dentro da exigência religiosa de literalidade. Através da Lingüística, foram estabelecidas categorias gráficas da tradição escrita ocidental em línguas ágrafas, tais como a concepção de palavra, sentença, parágrafo e texto. Essa relação entre Lingüística e escrita alfabética está explicitada no manual de tradução bíblica para missionários de Eugene Nida:

"In terms of the scientific analysis of the language, the alphabet represents the phonological system, the writing of word units concerns the morphological features of the language, and the punctuation entails an analysis of the syntactic structure" (Nida, 1947:100)

\section{2 - A formação de texto autônomo em línguas ágrafas através da Lingüística}

A maneira pela qual os conceitos lingüísticos foram introduzidos no mundo missionário pode ser aproximada à história da formação da concepção de "texto autônomo" na tradição ocidental. Segundo 
Olson (1991a), autor dessa proposta, houve numa primeira fase a constituição da letra através da criação do alfabeto grego, que, com a introdução de símbolos para vogais, estabeleceu um sistema de escrita que permitia a leitura verbatim. Em um segundo momento, com a invenção e difusão da tipografia, as noções de sentença e de texto foram consideradas como tendo apenas uma interpretação possível e determinada exclusivamente pelos elementos lingüísticos presentes no enunciado.

A periodização proposta por Olson para a tradição ocidental de escrita pode ser oportuna para ilustrar a forma de uso da Lingüística como padrão de escrita para línguas ágrafas no interior do movimento missionário de tradução bíblica entre o século XIX e XX. Não pretende ser uma história da escrita em geral, mas apenas o seu percurso em um domínio institucional, o das missões e sociedades bíblicas.

A) Formação da categoria de letra em línguas ágrafas

$\mathrm{Na}$ formulação da categoria de letra no contexto missionário, a Lingüística entrou primeiro como fonética articulatória e depois como fonologia. Esses dois momentos podem ser encontrados em dois trabalhos produzidos por ou para missionários: o livro de Lepsius de 1863 e artigos de Kenneth Pike, membro do SIL, na década de 30

Um exemplo do uso da fonética articulatória para formulação do conceito de letra no domínio missionario é o livro de Lepsius (Standard Alphabet for reducing unwritten languages and foreign graphic systems to a uniform orthography in European letters) (1863). O uso da fonética articulatória como padrão de letra veio responder à procura de uniformidade ortográfica no domínio missionário através do estabelecimento de um alfabeto standard.

"Uniformity is always the main object of the Standard Alphabet" (Lepsius, 1863:10)

Anterior ao livro de Lepsius, a formulação de um alfabeto universal para ser usado nas traduções para línguas ágrafas tinha sido tema de uma reunião entre missões inglesas em 1848, porém, sem 
ainda fazer uso da Lingüística. A reunião teve como resultado o documento "Rules of reducing unwritten languages to alphabetical writing in Roman characters, with reference especially to the languages spoken in Africa", assinado pelo Rev. Henry Venn, da Church Missionary Society. A preocupação dessas missões era a existência, entre os missionários, de uma variedade de notações ortográficas usadas para uma mesma língua.

\begin{abstract}
"Each translator having to choose his own system, it has not unfrequently happened that two or more persons engaged upon the same language have adopted different systems. This has prevented, in a great measure, the mutual assistance, which the parties might have rendered each other; and has retarded the formation of primers and educational works, and the translation of the Holy Scriptures" (Rules. Lepsius, 1863:40).
\end{abstract}

A proposta de Lepsius junto a Church Missionary Society foi usada principalmente na África e em menor número na Índia, onde a existência de outros sistemas de escrita foi fator de resistência às tentativas de romanização.

Um segundo momento da formulação do conceito de letra no contexto missionário foi a sua concepção como fonema. Essa formulação foi instituída pelo SIL no final da década de 30 e se tornou o seu modelo ortográfico. A visão da fonologia como modelo de ortografia ("para cada fonema, um grafema") está presente no título da obra de Kenneth Pike (Phonemics, a technique for reducing languages to writing).

Uma das primeiras versões do modelo ortográfico do SIL baseado na fonologia é o artigo "Practical suggestions toward a common orthography for Indian Languages of Mexico for education of the natives within their own tongues", de Kenneth Pike (1938) em um periódico dos indigenistas mexicanos (Boletim do Instituto Mexicano de Investigaciones Lingüísticas).

O interesse do SIL pela fonologia enquanto forma de estabelecer ortografias determinou o estilo teórico seguido pela missão nessa área da Lingüística. Não houve, por exemplo, lugar para modelos 
teóricos que trabalhassem com traços fonológicos (+ /- grave, etc), menos oportunos para determinar letras. A preferência foi sempre pelos modelos teóricos que trabalhassem com o fonema enquanto unidade discreta.

Se a fonética articulatória servia como um recurso para manter uniformidade, o uso da fonologia como modelo ortográfico respondia à exigência de homogenização das variações dialetais, estabelecendo um processo de estandardização nessas línguas. Respondia assim a uma exigência da escrita tipográfica.

Dessa maneira, as regras ortográficas presentes em Lepsius ("uma letra para cada som") e em Pike ("uma letra para cada fonema") responderam ao critério de não-ambigüidade lexical próprio do modelo de escrita autônoma. Por exemplo, no uso do conceito de fonema, a metodologia de se procurar "pares mínimos" tinha como eixo eliminar ambigüidades lexicais, ao estipular que se deve distinguir os sons em letras diferentes, desde que esses sons correspondessem a mudanças no significado de uma palavra.

B) Formulação da categoria de sentença em línguas ágrafas

A formulação de uma escrita autônoma nas línguas ágrafas por meio de conceitos da Lingüística se estendeu da letra para sentença através do livro Bible translating. An analysis of principles and procedures, with special reference to aboriginal languages, um manual para missionários-tradutores escrito por Eugene Nida em 1947. Seu autor, então membro do SIL, assinava o livro como Secretário de Versão da American Bible Society, responsável pela publicação do livro.

O manual de tradução para missionários incorporava o conceito de sentença-tipo de Bloomfield (1970) nas discussões sobre fidelidade de uma tradução. O uso do conceito representava o suposto de que o "sentido está na sentença".

O uso do conceito de sentença de Bloomfield como critério para a tradução modificaria as idéias vigente no guia de tradução da ABS de 1932. Este tinha a palavra como principal noção metalingüística usada na discussão de fidelidade. Manter-se fiel era basicamente uma 
questão de não excluir termos do texto original ou de não incluir outros que não estavam ali presentes. Literalidade era um valor a se conservar na tradução e a "tradução literal" representava um recurso legítimo.

"Every version should be as literal as the idiom of the language will permit" (ABS, 1932:7 em Nida, 1947:296)

Com a introdução do conceito de sentença o que era antes concebido no ABS como uma forma de tradução fiel - a tradução literal - deixou de sê-lo na teoria de base lingüística do SIL. A incorporação do conceito de sentença estabelecia uma crítica à "tradução literal", que apenas dispunha da noção de palavras isoladas, e não do seu agrupamento em sentença e das restrições na sua maneira de combinar.

A crítica à tradução literal não representou entretanto um abandono da noção de sentido literal, mas a sua redefinição em novos termos, agora considerada como "tradução idiomática". Esta nova concepção de fidelidade no interior do movimento missionário de tradução bíblica se delineou em torno aos princípios do literal no interior da Lingüística:

i) o sentido definido como imanente às formas lingüísticas, independentemente da situação de uso;

ii) o sentido de um enunciado como equivalente à análise componencial:

"The second method by which to validate the meaning of potential key terms is through componential analyses. This is especially useful when there are several potential terms for God or sin or devil and it becomes important to differentiate as precisely as possible the meaning components that distinguish terms which are in the same semantic set." (Beekman, 1980b:36).

iv) a função de representação como fundamento do significado.

Este último pressuposto está presente na concepção privilegiada de "compreensão literal e histórica" (Beekman/Callow, 1974) 
do texto bíblico, no qual se postula que este deve ser compreendido como uma narrativa histórica, ou seja, como um relato de uma determinada sucessão cronológica de eventos ocorridos num tempo e lugar determinado.

Houve um recrudescimento da tendência literalista na forma de interpretação bíblica, se for observado o estilo editorial adotado pelo SIL nas publicações do Novo Testamento em línguas ágrafas. Enquanto as edições da ABS aceitavam o uso de notas de página e itálicos para apresentar interpretações alternativas ao texto original ou para indicar que a tradução de uma expressão não era considerada um equivalente adequado, no SIL, não se fará uso desses recursos gráficos para indicar polissemias.

"(...) the ambiguities arising from the original and those arising from the receptor language are both removed in an idiomatic translation whenever one of the meanings is not compatible with the focus of the passage." (Beekman, 1965:7)

Para a missão, um Novo Testamento na língua indígena deverá ter o status de texto único, sem ambigüidades. Por esse motivo, não se indicam nas suas edições da Bíblia as leituras divergentes entre os comentadores. As únicas ambigüidades da Escritura que se conservam nas traduções são aquelas que caracterizam as diferenças entre as denominações que participam da missão, como forma de não causar conflitos internos.

C) Formação do conceito de parágrafo e texto em línguas ágrafas

Posteriormente, outros conceitos do mundo gráfico foram introduzidos por meio da Lingüística, tais como a noção de parágrafo (Laurialt, 1957) e a de discurso (Callow, 1974). A necessidade da formulação do conceito de parágrafo na prática do tradutor missionário se deve ao fato de que o modelo de Bíblia adotado foi o da sua organização por meio de parágrafos.

Em resumo, a Lingüística supriu as missões de um modelo de escrita de natureza autônoma, que concebia que todo o sentido é dado por completo e somente pelo texto, preenchendo assim a 
expectativa religiosa de que o texto é o seu próprio intérprete. O uso missionário da Lingüística pode ser interpretado como um reforço a um traço religioso, que é a exigência do literal como critério de fidelidade para a tradução bíblica. A ciência lingüística se torna assim moeda corrente entre missionários tradutores e seus revisores na discussão e avaliação da questão da fidelidade à Palavra Revelada.

A Lingüística, no contexto missionário, foi portanto uma racionalidade dirigida às perguntas e aos valores do público evangélico.

\section{6 - O PAPEL DA ORALIDADE NA SOCIALIZAÇÃO DO TEXTO AUTÔNOMO: O DIÁLOGO DO COMPREHENSION CHECK COMO EVENTO LITERÁRIO}

A posição do historiador de religiões W. Graham (1987) de que os valores de sagrado e de autoridade das Escrituras não existem sem o envolvimento de práticas sociais orais pode ser levada para a experiência da escrita missionária. Ainda que esta tenha como ideal produzir uma escrita autônoma - através da introdução da figura do livro, da opção pelo alfabeto, da fixação de uma única interpretação válida, etc., - parte fundamental da socialização do valor de autonomia se dá pela oralidade. Alguns eventos literários específicos da prática missionária são os responsáveis pela socialização dessas regras e concepções de escrita.

Uma das interfaces orais do texto autônomo religioso é o comprehension check, que será analisado como um evento de leitura que reproduz a concepção de leitura própria do movimento missionário de tradução bíblica. A escolha da análise de uma situação de leitura é por ser esta a habilidade enfatizada pela campanha missionária de alfabetização. Essa situação de leitura será descrita através de artigos do periódico Notes on Translation, uma publicação do SIL escrito por e para missionários-tradutores.

O comprehension check é uma situação de leitura do texto bíblico, que envolve o missionário e o ajudante da tradução (um falante nativo). Antes de sua impressão, uma passagem traduzida é 
lida para ou pelo falante nativo e, por meio de diferentes atos de fala, o missionário verifica se a passagem lida foi entendida de maneira canônica. Por exemplo, pede-se ao falante nativo que conte o que leu ou ouviu (tell-it-again/Hook, 1980), que responda perguntas (questioning technique/Hohulin, 1982:28; teaching questions / Headland, 1981:2) ou traduza trecho por trecho na língua franca comum entre ele e o missionário. Um dos atos de fala mais rotineiro do comprehension checké o que ocorre através da pergunta.

"It is hoped that preparing and applying such lists of questions will become a routine part of a translator's preparation in the language before he is far along in his translation program" (Beekman, 1980a:6)

O comprehension check refere-se portanto à situação em que o tradutor verifica o sentido da tradução em uma língua que lhe é estrangeira através de um diálogo com o falante nativo. No caso de o missionário obter uma resposta não esperada, ele modifica o texto traduzido. A cada modificação do texto, a pergunta antes respondida incorretamente deve ser refeita. O diálogo só é concluído quando o missionário obtém uma resposta que tenha as mesmas condições de verdade que ele considera possuir o texto original. Uma vez que ele chegue à resposta desejada, supõe que o texto traduzido expressa o sentido correto. Nessa situação, ele pode passar para outras perguntas (Waltz, 1981)

Os artigos do Notes on Translation dão alguns exemplos da rotina desse diálogo:

"The procedure is to read the passage to the language assistant once or twice. Often it helps to have him translate it sentenceby-sentence back into a second language they both know. In this way, the language assistant fixes the main events or points in his mind. Then the translator may ask him to tell back in his own words as much as he remembers. The hope is that he will give back the high points of the story" (Rountree, 1984:5). 
"Choose a passage and prepare a list of questions on some of the facts of the passage. The questions should be fairly short; they should be questions which require a short, factual answer. Do not use questions which ask for opinions". (Barnwell, 1984:40)

"I would advise a consultant to frequently ask his question on a passage first, before the passage is read. This is especially true if a passage is lengthy and/or complex. If this is done, the LA [Language Assistant] can focus his attention on the specific problem in view without being distracted by a minutiae of details not pertinent to the question/problem at hand" (Hohulin, 1982:30)

O conceito de evento literário de Brice Heath (1990) pode ser aplicado ao diálogo do comprebension check em virtude das condições que apresenta dentro do processo de tradução bíblica missionária:

a) funciona como a interface oral de um texto escrito:

Comprehension check é um diálogo que envolve necessariamente um texto escrito (a tradução), a respeito do qual gira todo o diálogo através de diferentes atos de fala.

b) possui regularidade:

O comprehension check ocupa metade do tempo de tradução do Novo Testamento (Rountree, 1984:3), cuja previsão oficial é de cerca de 15 anos, mas que em alguns países, como o Brasil, pode chegar a 28 anos.

c) é um diálogo obrigatório:

O comprehension check é uma situação comunicativa obrigatória no processo de tradução bíblica no SIL. Em alguns contextos, ele tem um caráter oficial, quando acompanhado pelo consultor de tradução designado pela missão. O consultor está encarregado de aprovar ou não o texto para publicação a partir do resultado do diálogo.

O consultor, que não conhece a língua em questão, acompanha a tradução através do back-translation, também chamado semiliteral translation. Este consiste numa tradução para o inglês do Novo 
Testamento traduzido na língua indígena. Seu papel é ser uma tradução de controle institucional na qual a missão verifica a correção da tradução na língua indígena antes de dar a permissão para impressão.

"The purpose of back-translations, as considered here, is to provide the consultant in advance with an adequate tool to use in checking the translation with regard to omissions and additions, exegesis, application of translation principles, grammatical matters, possible comprehension problems and possible naturalness problems. The back-translation must therefore give as accurate a picture of the RL [Receptor language] text as possible." (Moore, 1980:12)

Nas situações de consultoria, o diálogo entre consultor e missionário se dá em inglês, enquanto o diálogo entre o falante nativo e o missionário ocorre na língua da tradução.

Em relação ao ajudante de tradução que participa do diálogo do comprehension check, ele é uma peça fundamental na estratégia da tradução bíblica do SIL: espera-se que ele seja a pessoa que viabilizará a Igreja evangélica na comunidade. A evangelização do SIL se concentra nesses indivíduos, considerados como os agentes evangélicos em potenciais da sua comunidade.

"The translator, in the very process of making the translation, has a built-in Bible teaching ministry to those working with him. Many of these become the leaders and teachers of the Christian community that will use the translation. The translator not only has the opportunity to disciple and train them, but to share a vision of church planting and church growth. They, in turn, take what they have learned and the Scriptures they have helped translate and share them with others" (Introduction to the Policies and Practices of Wycliffe Bible Translators, INC"/1975 apud Dye, 1979:17).

O diálogo do comprehension checké visto pelos missionários como a forma mais eficaz de curso bíblico que o missionário dispõe no processo de evangelização: 
"(...) the most important Bible teaching goes on during the process of translation and checking the translated Scriptures." (Dye, 1979:17)

As raízes culturais do comprebension check como evento literário podem ser encontradas na tradição de cursos bíblicos das Igrejas fundamentalistas americanas (Zinsser, 1986). Essa origem comum está presente, por exemplo, na possibilidade de se fazer uso dos livros utilizados nos cursos bíblicos para o público americano como modelo para as perguntas a serem usadas comprebension check no contexto missionário (Barnwell, 1984:40).

Algumas das características do curso bíblico enquanto evento literário das Igrejas evangélicas americanas (Zinsser, 1986) podem ser encontradas no comprehension check:

i) Ambos fazem uso de práticas orais (ouvir, memorizar, responder, etc.), como forma de socialização da forma correta de ler o texto bíblico.

O objetivo do diálogo do comprehension check, à semelhança do curso bíblico, é estabelecer um acordo a respeito da forma de ler o texto bíblico. Por meio desse diálogo, ocorre a socialização dos critérios de relevância que o missionário usa, para que o texto seja compreendido.

Um exemplo é o papel das perguntas no diálogo do comprehension check: elas são uma modalidade de ensino da maneira pela qual se deve interpretar o texto bíblico. A pergunta dirige o conteúdo proposicional que a resposta deve dar. O sucesso dessa modalidade de diálogo depende dos interlocutores entrarem em acordo em relação às condições proposicionais requeridas entre os dois atos. É preciso que a resposta do falante nativo seja relevante em relação ao que deseja saber o missionário (máxima de relação). Por exemplo, quando se quer que uma passagem seja vista como a descrição de fatos, as perguntas são acompanhadas por quem?, que?, como?, quando?, etc. (Barnwell, 1984:40). A forma interrogativa (question word) substitui uma informação, que se procura obter pela 
resposta e dirige a resposta para um determinado conteúdo referencial.

"As Bible translators we are trained to ask our translation helpers and other speakers of the language questions such as: who? what? how?, when?, where? and why?" (Waltz, 1979:33)

Compreender a tradução significa responder corretamente às perguntas feitas pelo missionário. Quando o texto bíblico for uma narrativa, o informante deve recontar ou responder sobre quais são os eventos principais em foco. No caso do texto ser um discurso didático, o informante deve reproduzir o que está sendo ensinado.

ii) O principal ato de fala tanto no curso bíblico como no comprebension check é a pergunta didática, não havendo lugar para perguntas com função especulativa a respeito dos textos (Zinsser, 1986:63).

As condições pragmáticas da pergunta no interior do comprehension check são de pergunta didática (fechada ou de exame), que se caracteriza pelo locutor possuir antecipadamente qual é a resposta correta que espera à sua pergunta (Searle, 1969:66). A pergunta no comprebension check não deposita no ouvinte o critério de correção da resposta. O missionário, ao fazer a pergunta, tem de antemão a resposta que procura: "the translator knows the information he is seeking and has formulated his question" (Rountree, 1984:9).

No Notes on Translation, existem listas de perguntas já preparadas para cada texto; outro modelo de perguntas para o comprehension checké aquele contido nos livros de cursos bíblicos em inglês (Barnwell, 1984:40)

Em alguns casos, a modalidade de pergunta didática tem que ser ensinada pelo missionário, por não fazer parte do repertório comunicativo das comunidades:

"We have had considerable difficulty, however, in using teaching questions. We finally concluded that such questions are not used 
in Trique culture. The only two uses we have found for questions are to obtain information and to scold. The only Triques who understand the use of teaching questions are the ones who have attended school, mainly younger men" (Hollenbach apud Headland, 1981:2).

iii) Por fim, curso bíblico e comprehension check socializam o texto bíblico como autoridade textual ("this strongly framed pedagogy reinforces the creation and maintenance of textual authority") (Zinsser, 1986:68).

Uma diferença entre essas duas modalidades de diálogo é que enquanto os cursos bíblicos das Igrejas fundamentalistas enfatizam, pelas perguntas, a sua aplicação nas situações cotidianas do indivíduo, o comprebension check enfatiza a compreensão da narrativa dos fatos, concebido como expressão do sentido literal. Em ambos os casos, eles são eventos literários fundamentais para a socialização da forma correta de leitura do texto bíblico.

O comprehension check, ao funcionar como socialização das regras de como se deve ler o texto bíblico, inclui nessas lições a concepção de "texto autônomo", aqui entendido como independente do background do ajudante de tradução. Algumas das regras que socializam o falante nativo para esse gênero literário são:

i) O falante nativo deve ser ensinado a referir-se exclusivamente ao que "está" no texto:

"I have long suspected that respondents to comprehension questions will be more helpful to the translation project if they are trained to know just what is expected, how to look in the passage for the answer that is there rather than answering them their general background knowledge" (Moore \& Moore, 1984:17). [grifo do autor]

ii) Deve ser ensinado a não responder em relação a sua própria vida, evitando uma perspectiva subjetiva na resposta. O aprendizado consiste em separar o que está no texto do que é a vida pessoal do informante: 
"Do not use questions which ask for opinions." (Barnwell, 1984:40)

"(...) in spite of the fact that the wording of the question focused on the situation at Corinth and what the Corinthian Christians were meant to understand or do, answers bypassed the situation at Corinth and were given in terms of what 'we' should do." (Strange, 1980:6)

iii) As referências temporais e espaciais no texto bíblico devem ser consideradas independentes do contexto imediato de interação. É importante que o fato no texto seja entendido como algo que ocorreu em lugares distantes. Para socializar essa forma de leitura, algumas sociedades bíblicas incluem o mapa do Oriente Médio na edição da Bíblia, como na passagem abaixo:

"In their ancient religious songs [...] scores of places occured, but then nobody cared, for it was all the region of myth and fairyland. How many natives have said to me "What! Jerusalem actually in existence now?'. Five thousand sets of maps were accordingly forwarded to accompany the third edition" (Canton, 1904:vol.5:9)

iv) O diálogo procura socializar determinadas unidades gráficas, tal como a do parágrafo:

"Of greatest usefulness to the consultant in evaluating the level at which a translation is correctly comprehended is the elicitation of the content summaries of paragraphs or larger units. Whether dealing with epistle or narrative text, each paragraph contains within it some information of lesser significance. Each paragraph, then, is subject to summarization by a process of selecting that information which is of greater significance to the author's intent." (Beekman, 1980a:4)

Em suma, o comprebension check tem como função ensinar a maneira como o texto bíblico dever ser interpretado. Pelo diálogo permanente de pergunta e resposta, o ajudante é guiado até chegar à resposta desejada pelo missionário. Ele ensina quais são suas expectativas em relação à resposta, e por essa via, à interpretação 
que se deve dar ao texto. Nessas regras se inclui o ensino do conceito de texto autônomo, que consistirá no sentido que o missionário considera que está no texto.

Por fim, o comprehension check tem importância como modelo de leitura do texto bíblico depois de sua impressão. Na ausência do missionário, as perguntas formuladas durante o comprehension check permanecem como o guia de leitura e interpretação do texto bíblico.

\begin{abstract}
"Similar questions kept the Manobo church going during our fiveyear leave of absence, probably because they provided some minimal structure for an ongoing use of the Scripture" (Johnston, 1980:4)
\end{abstract}

\title{
7 - CONCLUSÃO
}

A proposta do trabalho foi analisar diferentes experiências de escritas alfabéticas em línguas ágrafas formuladas pelas missões evangélicas desde o século XIX como tendo uma origem comum no movimento religioso da difusão da Bíblia e compartilhando de um mesmo modelo de escrita. Nessa modalidade de evangelização pela tradução bíblica, o missionário assumiu vários papéis relacionados à escrita nas línguas ágrafas. Ele é o responsável pela elaboração de categorias gráficas nessas línguas, pela produção de textos escritos (traduções bíblicas e cartilhas) e pela alfabetização.

Essas campanhas de alfabetização foram criadas dentro dos valores, concepções e práticas de escrita próprios do protestantismo, tais como, considerar o domínio da habilidade de leitura como parte essencial da conversão, privilegiar o livro como forma de uso da escrita, enfatizar o valor do sentido literal e relacionar leitura à obediência.

Na análise da escrita missionária de tradição protestante, a discussão a respeito do valor de autonomia no âmbito da escrita não poderia estar ausente, já que o protestantismo é considerado um dos focos da formação dessa concepção de escrita (Olson, 1991a). Por isso, duas correntes teóricas divergentes sobre a questão da 
autonomia na escrita foram revisadas e consideradas relevantes na análise da tradição de escrita missionária de base lingüística. A preocupação da análise foi combinar as duas correntes, fazendo distintas opções em cada uma delas.

Em relação ao modelo autônomo da escrita, foram resgatados os seguintes pontos:

a) A relevância do valor de autonomia como forma de análise da noção de sentido literal no interior da política de evangelização pela tradução bíblica. A suposição da análise foi que sentido literal se expressa através das condições apontadas para uma escrita autônoma.

O conceito de texto autônomo permitiria ainda explicar a preferência missionária pela elaboração de sistemas alfabéticos para as línguas ágrafas e o lugar importante da Lingüística como modelo de escrita no mundo evangélico.

b) Interesse por histórias intelectuais de tecnologias de comunicação

Ao traçar uma história das escritas alfabético-tipográficas em línguas ágrafas criadas por missões evangélicas a partir do século XIX, conservou-se a dimensão histórica própria dos autores do modelo autônomo. Entretanto, foi excluída dessa história a tese de caráter psicológico referente às mudanças na forma de pensamento (Olson, 1991b) ou na forma de organização do sensorium (Ong, 1986). Optou-se por traçar uma história desses alfabetos enquanto tecnologias de comunicação que causam mudanças apenas ao nível institucional (abordagem de Eisenstein/apud Olson, 1991b). O domínio institucional analisado aqui foi o do movimento missionário de tradução bíblica. O tipo de mudança que se procurou identificar foi em relação ao modelo ideal de escrita projetada para as línguas ágrafas.

c) Atenção ao sistema de escrita enquanto unidade de análise

O modelo ideológico não trabalha com a dimensão dos sistemas de escrita, por considerá-los irrelevantes, quando analisados independentes das práticas comunicativas nas quais estão imersos. 
No caso da análise da escrita missionária foi relevado o predomínio do sistema alfabético latino usado nesta tradição, porém sem pretender que esta presença majoritária do alfabeto seja uma expressão da qualidade intrínseca desse sistema de escrita. Apenas se quis marcar que essa tradição evangélica de escrita identifica em um sistema de escrita em particular - o alfabeto romano - os parâmetros que lhe são fundamentais, tais como a possibilidade de leitura verbatim e a de não ambigüidade lexical.

Quanto ao modelo ideológico, algumas das questões tomadas emprestadas para a análise da escrita missionária evangélica foram:

a) Atentar para o específico no estudo da escrita

Essa foi a preocupação que se teve ao fazer uso do valor de autonomia na análise da escrita missionária. Escrita autônoma foi definida não como um conceito que retrata as qualidades da escrita alfabética em geral, mas como um padrão cultural próprio da tradição protestante.

Texto autônomo foi tomado como um tipo ideal formado por um conjunto de concepções e práticas sobre a escrita, no qual estaria incluída a eleição de determinados tipos de uso da escrita: predomínio do livro, leitura verbatim, eliminação de heterófonos, etc. Esse padrão de escrita não necessariamente está presente na prática do missionário em sua atuação com os grupos a converter, mas está nos documentos oficiais que formulam como deve ser sua prática no tocante à produção de uma escrita.

b) Interesse em apontar a interconexão entre oralidade e escrita através do conceito de evento literário

A análise do comprehension check procurou tornar visíveis práticas orais que envolvem o uso da escrita missionária. Este evento de leitura aponta a importância da oralidade na formação da idéia de texto autônomo. Portanto, negou-se a existência de uma escrita autônoma que não tenha expressão ao nível da oralidade.

Enquanto os documentos das missões e sociedades bíblicas apontam a importância do valor de autonomia da escrita missionária, 
não necessariamente será esse o valor absorvido pelos grupos a serem convertidos. Alguns movimentos messiânicos que surgiram em diferentes partes do mundo em resposta ao movimento missionário de tradução bíblica sugerem que a recepção dessa escrita teve um sentido contrário. Em oposição à idéia da completude do discurso bíblico, alguns movimentos messiânicos identificaram como incompleto o texto bíblico divulgado pelos missionários. Esse parece ser o caso dos cargo cult na Melanésia (Clammer, 1976, Melgitt, 1968, Street, 1995) e o movimento religioso “Aleluia” em Roraima e Guiana Inglesa.

O movimento Aleluia surgiu entre grupos Caribe na Guiana Inglesa e em Roraima a partir da segunda metade do século XIX. Brett, um missionário-tradutor contemporâneo ao surgimento desse movimento, assim o descreve:

"About this time a remarkable imposture was practised upon the Indians in that part of Guiana. A person pretending to be the Lord went into the interior with some deluded followers, and established himself in the upper part of the Masaruni. From this distant spot, he sent emissaries into the neighbourhood of all the missions, calling on the Indians to quit their homes and provisiongrounds, and go to him. They were told that they should possess lands which would yield a large crop of cassava from a single stick, and various other absurdities, very alluring to the Indolent Indian" (Brett, 1868:181).

Nas narrativas dos Caribe da Guiana a respeito da origem do Aleluia, Deus apareceu para um Macuxi para lhe transmitir o verdadeiro texto, devido os missionários estarem enganando o grupo e escondendo-lhes sua palavra. Deus lhe deu diretamente o Aleluia, além de um vidro de remédio, canções e um pedaço de papel, que seria a Bíblia dos índios (Butt, 1959:38). Nas várias versões da origem do Aleluia, Deus se comunica diretamente com os índios através de cartas ou pedaços de papéis.

O movimento dos Cargo cult surgiu na década de 50 em várias regiões das ilhas do Pacífico com promessas de barcos cheios de mercadorias para os nativos. O movimento é analisado como uma 
resposta ao fracasso dos melanésios de obterem com o Cristianismo a riqueza e o poder dos europeus. Por mais que eles participassem dos rituais cristãos, que seus filhos participassem das escolas, as pessoas permaneciam igualmente pobres. O movimento do Cargo cult interpretará que a pobreza e a ausência de poder ocorriam porque os missionários não estavam ensinando toda a Bíblia e estariam escondendo páginas importantes onde estavam alistados os nomes secretos de Deus (Melgitt, 1968:303)

"The failure of the Book to bring the desired Cargo is sometimes attributed to its incompleteness, to the fact that the all important pages have been torn out and hidden by their white masters who want to keep the secret knowledge to themselves" (Goody, 1968:298)

A incompletude semântica do texto autônomo também está presente na versão mais atual da obra de Olson (1997), onde o autor pondera que o sistema alfabético tem limitações para dar conta da força ilocutória de um texto. O alfabeto fica assim definido como uma tecnologia de comunicação marcada inexoravelmente pela incompletude semântica: "a escrita representa facilmente o ato locucionário, mas dá uma representação sempre insuficiente da força ilocucionária. Recuperar essa força passa a ser um problema fundamental da leitura" (Olson, 1997:109).

\section{NOTAS}

${ }^{1}$ Todo membro do SIL é também da Wycliffe Bible Translators. Para acompanhar historicamente as diferentes formas de relação entre o SIL e WBT, ver as análises de David Stoll (1981/1985). 


\section{REFERÊNCIAS BIBLIOGRÁFICAS}

AMERICAN BIBLE SOCIETY. A guide for translators, revisers and editors working in connection with the American Bible Society. New York, apêndice de Nida, Eugene Bible translating (1947), 1932.

ARNOVE, Robert F.; GRAFF, Harvey J. National literacy campaigns. Historical and comparative perspectives. Plenum Press, 1987.

BARNWELL, Katherine. Tradução bíblica. Um curso introdutório dos princípios básicos de tradução. Brasília. SIL, 1979.

BARNWELL, Katherine. Ten ways of testing your translation. Notes on Translation, n.100, p. 36-44. SIL, 1984.

BARROS, M. Cândida D. M. Um caso de Lingüística missionária: Summer Institute of Linguistics. Tese de doutorado. Unicamp, 1983.

BARROS, M. Cândida D.M. Uma modalidade de pergunta missionária. Cadernos de Estudos da Linguagem, julho/dez. Unicamp n.27,p.5-25, 1994.

BARTON, David. Literacy. An introduction to the ecology of written language. Blackwell, 1995.

BARTON, D.; PADMORE, S. Roles, networks, and values in everyday writing, p.58-77. In: Barton.D.; Ivanic, Roz. Writing in the community. Sage Publications, 1991.

BEEKMAN, John. Translation consultation. Notes on Translation, n.11, p.1-18. SIL, 1964.

BEEKMAN, John. Idiomatic versus literal translations. Notes on Translation, n.18, p.1-15. SIL, 1965.

BEEKMAN, John. Three focuses on consultation procedures. Notes on Translation, n.81, p.2-14. SIL, 1980a.

BEEKMAN, John. Anthropology and the translation of New Testament key terms. Notes on Translation. n.80, p.32-42. SIL, 1980b.

BEEKMAN, John; CALLOW, John. Translating the Word of God. With scripture and topical index. Zondervan Publishing House, 1974.

BESNIER, Niko.Literacy, emotion and autbority. Reading and writing on a Polynesian atoll. Cambridge University Press, 1995.

BLOOMFIELD, Leonard.Language. Unwin University Press, 1970.

BLOOMFIELD, Leonard. O significado (29-41). In: Dascal, Marcelo (Org.). Fundamentos metodológicos da lingüística, vol.III. Semântica, Unicamp, Campinas, 1982.

BOYARIN, Jonathan. Ethnography of reading. University of California Press, 1992. 
BRETT, W.H. The Indian tribes of Guiana: their condition and habits: with researches into their past bistory, superstitions, legends, antiquities, languages. Bell and Daldy, 1968.

BRITISH AND FOREIGN BIBLE SOCIETY. Rules for the guidance of translators, revisers and editors working in connection with the British and Foreign Bible Society. Bible House Papers no.VIII. Tentative edition. 1906. London, 1906.

BRITISH AND FOREIGN BIBLE SOCIETY. Rules for the guidance of translators, revisers and editors, working in connection with the British and Foreign Bible Society. Bible House Papers, n.VIII. London, 1925.

BUTT, Audrey J. The Birth of a religion. Timebri, Part 1:37-48; part 2: 23-35. Guiana, 1959.

CALLOW, Kathleen. Discourse considerations in translating the Word of God. Zondervan Publishing House. Michigan, 1974.

CAMARA, Joaquim Mattoso. 1977. Comentário do co-relator J. Mattoso Camara Jr. ao Relatório (Parte Geral) do Prof. Aryon Rodrigues. p.63-65. In: Schaden, Egon (Ed.). Homem, cultura e sociedade no Brasil. Seleções da Revista de Antropologia, Vozes, (Estudos Brasileiros I), 20 ed.

CANTON, William. A bistory of the British and Foreign Bible Society. London: John Murray/The Society, 1904.

CLAMMER, J. R. Literacy and social change. A case study of Fiji. Leiden: E.J. Brill, 1976.

DYE, T.Wayne. The Bible translation strategy: an analysis of its spiritual impact. SIL, Papua New Guinea, 1979.

FREIRE, Carlos Augusto da Rocha. Indigenismo e Antropologia. O Conselho Nacional de Proteção aos Índios na gestão Rondon (1939-1955). Rio de Janeiro: Dissertação de Mestrado, Museu Nacional, 1990.

FUNAI. Normas para educação dos grupos indigenas. Portaria n.75/N, de 6/ 7/72. Mimeografado anexo ao material do curso de Lingüística do SIL em 1976, 1972.

GIRDLESTONE, R. B. Suggestions for translators, editors and revisers of the Bible. London: Hatchards, 1877.

GOODY, Jack. Literacy in traditional societies. Cambridge University Press, 1968.

GOODY. J.; WATT, I. The consequences of literacy. In: Goody, J. Literacy in traditional societies. Cambridge University Press, 1968. 
GRAFF, Harvey J. The legacies of literacy: continuities and contradictions in western society and culture (p.61-86). In: Literacy, society and schooling. $A$ reader. Editer by Castell, Suzanne de; Luke, A. and Egan, Kieran. Cambridge University Press, 1986.

GRAHAM, Willian. Beyond the written word. Oral aspects of Scriptures in the History of Religion. Cambridge University Press, 1987.

GUDSCHINSKY, S. Handbook of literacy. Glendale. SIL, 1951.

HARRIS, Roy. The language makers. London: Duckworth, 1980.

HAY, Rev. Alex Rattray. The Indians of South America and the Gospel. New York: Fleming H. Revell Company, 1928.

HEADLAND, Edna. Questions as a checking device for translations. Notes on Translation, n.83:2-9. SIL, 1981.

HEATH, Shirley Brice. Ways with words. Language, life and work in communities and classrooms. Cambridge University Press, 1990.

HEFLEY, James \& HEFLEY, Marti. Uncle Cam. The story of William Cameron Townsend, founder of the Wycliffe Bible Translator and the Summer Institute of Linguistics. Waco. Word Books, 1974.

HOHULIN, Richard. Questioning our questioning technique. Notes on Translation, n.91, p.28-32, SIL, 1980.

HOOK, Ann. A Fresh look at Consultant Procedures. Notes on Translation, n.80, p.2-21, SIL, 1980.

H[orace].B[anner]. Primeira cartilha gê-portugues. Posto Gorotire. 2 impressão, 1959.

INSTITUTO INDIGENISTA INTERAMERICANO. VII Inter-American Indian Conference, Brasilia, August, 1972.

JOHNSTON, Clay. A breakthrough in translation checking and a step toward objective quality standards: written questions which test sentence and paragraph propositions. Notes on Translation, n.78: 2-4, SIL, 1980.

KING, George Anthony. "In our tongues": a popular handbook to the translation work of the British and Foreign Bible Society. London: BFBS, 1900.

LAURIALT, James. Some problems in translating paragraphs idiomatically. The Bible Translator, vol. 8, p.166-175, 1957.

LEPSIUS, C.R. Standard alphabet for reducing unwritten languages and foreign graphic systems to a uniform orthography in Europeans letters. 2nd edition. London: Williams \& Norgate, (1863).

LINELL, Per. The Written language bias in Linguistics. 
LYONS, J. Semantics. Cambridge University Press, 1972.

McARTHUR, Harry. Asking the right questions. Notes on Translation, n.102, p.21-29, SIL, 1984.

MELGITT, M. Literacy in New Guinea and Melanesia. In: Goody, J. Literacy in traditional societies. Cambridge University Press, 1968.

MIGNOLO, Walter. Signs and their transmission: the question of the book in the New World. In: Elizabeth Hill Boone and Walter D. Mignolo (Eds.). Writing without words: alternative literacies in Mesoamerica and the Andes. Durham: Duke University Press, 1994.

MOORE, Bruce. Report of the translation consultants meeting for the America, Quito, April, 1979. Notes on Translation, n.79, p.8-23, SIL, 1984.

MOORE, Bruce \& MOORE, Paul. What is a passing grade on a comprehension test. Notes on Translation, n.101, p.14-27, SIL, 1984.

MORRIS, Henry. Literation and transliteration. Suggestions and notes by Henry Morris. Prepared at the Request of the Editorial sub-committee of the British and Foreign Bible Society. Bible House Papers n.V., British and Foreign Bible Society, 1901.

NEILL, Stephen et all. Concise dictionary of the Christian World Mission. London, 1970.

NIDA, Eugene. Bible Translating, an analysis of principles and procedures with special reference to aboriginal languages. New York: American Bible Society. 1947.

OLIVEIRA, Roberto Cardoso. Deve o Summer permanecer no Brasil? Religião e Sociedade, Rio de Janeiro, n.7, p.66-67, 1981.

OLSON, David, D. From utterance to text: the bias of language in speech and writing. In: Mamiani/Kennedy. Languages issues in literacy and bilingual/ multicultural education. Harvard Educational Review, 1991a.

OLSON, David. Literacy and objectivity: the rise of modern science. In: Olson, D.; Torrance, N. Literacy and orality. Cambridge University Press, 1991b.

OLSON, D. O mundo no papel. As implicações conceituais e cognitivas da leitura e da escrita. São Paulo: Ática, 1997.

ONG, Walter J. Orality and Literacy. The Technologizing of the Word. London: Methuen, 1982.

ONG, W. The presence of the Word. Some prolegomena for cultural and religious bistory. Minneapolis: University of Minnesota Press, 1986.

PIKE, Eunice. Ken Pike, scholar and Christian. Dallas: SIL, 1981. 
PIKE, Kenneth. Practical suggestions toward a common orthography for Indian languages of Mexico for education of the natives within their own tongues. Investigaciones Lingüísticas, t.V, n.1 e 2, p.86-97. Instituto Mexicano de Investigaciones Lingüisticas. Mexico, 1938.

PIKE, Kenneth. Phonemics, a technique for reducing languages to writing. Ann Arbor: University of Michigan Press, 1971.

REED, Rev. Charles E. B. The Bible work of the world. London: John F. Shaw \& Co., 1879.

ROMMETVEIT, Ragnar. On literacy and the myth of literal meaning. (13-39) In: Saljo, Roger (Ed.). The written world. Studies in literate thought and action. London: Springer-Verlag, 1988.

ROUNTREE, Catherine. A preliminary guide to comprehension checking. Notes on Translation, n.101. p.3-14, SIL, 1984.

SCHAUER, Stan. Checking through a written paraphrase. Notes on Translation, n.78, p.19-20, SIL, 1980.

SCRIBNER, S.; COLE, M. The psychology of literacy. Harvard University Press, 1981.

SEARLE, John. Speech acts. An essay in the philosophy of language. Cambridge University Press, 1969.

SERVIÇO DE PROTEÇÃO AOS ÍNDIOS. Relatório das atividades do Serviço de Proteção aos Índios. (datilografado), 1953/1954.

SMALLEY, William A.Translation as mission. Bible Translation in the modern missionary movement. Georgia: Mercer University Press, 1984.

STOLL, David. Words can be used in so many ways. In: Hvalkof, Soren; Aaby, Peter. Is God an American? An anthropological perspective on the Missionary work of the Summer Institute of Linguistics. Survival International/IWGLIA. Dinamarca/Inglaterra, 1981.

STOLL, David.1985. Pescadores de Hombres o fundadores de Imperio? DESCO/ Centro de Estudios y Promoción del Desarrollo. Lima 489 pp

STRANGE, David. An experiment in checking themes. Notes on Translation, n.78, p.4-18, SIL, 1980.

STREET, Brian. Literacy in theory and practice. Cambridge University Press, 1984.

STREET, Brian. Social literacies:critical approaches to literacy in development, ethnography and education. London: Longman, 1984.

SUMMER INSTITUTE OF LINGUISTICS. Plano para pesquisa lingüística nas línguas indígenas brasileiras (11-16). In: Museu Nacional. Setor de Lingüistica (Organizaçao e Objetivos), 1965. 
SUMMER INSTITUTE OF LINGUISTICS.Literacy in the '90s. The role of the Summer Institute of Linguistics, 1990.

THOMAS, James. Bible translation and diffusion: difficulties and achievements. The Bible House, 1900.

TOWNSEND, G. El aspecto romantico de la investigación lingüística. Peru Indigena, n.2, Instituto Indigenista Peruano, Lima, 1949.

UNITED BIBLE SOCIETIES. Scriptures of the World. New York, 1997.

WALLIS, Ethel Emily; BENNETT, Mary Angela. Two thousand tongues to go. The story of the Wycliffe Bible Translators. New York: Harper and Brothers Publisher, 1959.

WALTZ, Nate. The importance of asking questions.Notes on Translation, n.75, p.33-34, SIL, 1981.

WALTZ, Nate.1981. Written comprehension checks.Notes on Translation n.83, 13-18. SIL

WILLIAMS, Monier. Original papers illustrating the bistory of the application of the Roman alphabet to the languages of India. London, 1959.

ZINSSER, Caroline. For the Bible tells me so: teaching children in a fundamentalist church (55-71). In Schieffelin, B.; Gilmore, P. The acquisition of literacy: Ethnographic perspectives. Ablex Publishing Corporation. Norwood New Jersey, 1986. 